\title{
Optical backscattering properties of the "clearest" natural waters
}

\author{
M. S. Twardowski ${ }^{1}$, H. Claustre ${ }^{2}$, S. A. Freeman ${ }^{1}$, D. Stramski ${ }^{3}$, and Y. Huot ${ }^{2}$ \\ ${ }^{1}$ Department of Research, WET Labs, Inc., Narragansett, RI 02882, USA \\ ${ }^{2}$ Laboratoire d'Océanographie de Villefranche, UMR-CNRS 7093, Villefranche sur Mer, France \\ ${ }^{3}$ Marine Physical Laboratory, Scripps Institution of Oceanography, Univ. of California at San Diego, La Jolla, CA \\ 92093-0238, USA
}

Received: 13 July 2007 - Published in Biogeosciences Discuss.: 30 July 2007

Revised: 24 October 2007 - Accepted: 9 November 2007 - Published: 29 November 2007

\begin{abstract}
During the BIOSOPE field campaign OctoberDecember 2004, measurements of inherent optical properties from the surface to $500 \mathrm{~m}$ depth were made with a ship profiler at stations covering over $8000 \mathrm{~km}$ through the Southeast Pacific Ocean. Data from a $\sim 3000 \mathrm{~km}$ section containing the very clearest waters in the central gyre are reported here. The total volume scattering function at $117^{\circ}, \beta_{t}\left(117^{\circ}\right)$, was measured with a WET Labs ECO-BB3 sensor at 462, 532 , and $650 \mathrm{~nm}$ with estimated uncertainties of $2 \times 10^{-5}$, $5 \times 10^{-6}$, and $2 \times 10^{-6} \mathrm{~m}^{-1} \mathrm{sr}^{-1}$, respectively. These values were approximately $6 \%, 3 \%$, and $3 \%$ of the volume scattering by pure seawater at their respective wavelengths. From a methodological perspective, there were several results:

- $b_{b p}$ distributions were resolvable even though some of the values from the central gyre were an order of magnitude lower than the lowest previous measurements in the literature;

- Direct in-situ measurements of instrument dark offsets were necessary to accurately resolve backscattering at these low levels;

- accurate pure seawater backscattering values are critical in determining particulate backscattering coefficients in the open ocean (not only in these very clear waters); the pure water scattering values determined by Buiteveld et al. (1994) with a [1+0.3S/37] adjustment for salinity based on Morel (1974) appear to be the most accurate estimates, with aggregate accuracies as low as a few percent; and

- closure was demonstrated with subsurface reflectance measurements reported by Morel et al. (2007) within instrument precisions, a useful factor in validating the backscattering measurements.
\end{abstract}

Correspondence to: M. S. Twardowski

(mtwardo@wetlabs2.com)
This methodology enabled several observations with respect to the hydrography and the use of backscattering as a biogeochemical proxy:

- The clearest waters sampled were found at depths between 300 and $350 \mathrm{~m}$, from $23.5^{\circ} \mathrm{S}, 118^{\circ} \mathrm{W}$ to $26^{\circ} \mathrm{S}$, $114^{\circ} \mathrm{W}$, where total backscattering at $650 \mathrm{~nm}$ was not distinguishable from pure seawater;

- Distributions of particulate backscattering $b_{b p}$ across the central gyre exhibited a broad particle peak centered $\sim 100 \mathrm{~m}$;

- The particulate backscattering ratio typically ranged between $0.4 \%$ and $0.6 \%$ at $650 \mathrm{~nm}$ through the majority of the central gyre from the surface to $\sim 210 \mathrm{~m}$, indicative of "soft" water-filled particles with low bulk refractive index; and

- $b_{b p}$ showed a distinct secondary deeper layer centered $\sim 230 \mathrm{~m}$ that was absent in particulate attenuation $c_{p}$ data. The particulate backscattering ratio was significantly higher in this layer than in the rest of the water column, reaching $1.2 \%$ in some locations. This high relative backscattering, along with the pigment composition and ecological niche of this layer, appear to be consistent with the coccolithophorid Florisphaera profunda.

Moreover, results were consistent with several expectations extrapolated from theory and previous work in oceanic and coastal regions, supporting the conclusion that particulate and total backscattering could be resolved in these extremely clear natural waters.

Published by Copernicus Publications on behalf of the European Geosciences Union. 


\section{Introduction}

Morel et al. (2007) recently reported several optical properties from the South Pacific gyre near Easter Island, generally considered the clearest known naturally occurring waters (with the quotations in the title, after Morel et al. (2007) belying any presumption that there exist no clearer waters). In the Morel et al. (2007) study, a UV-visible radiometer was used to determine downward and upward planar irradiances at discrete depths, from which the diffuse attenuation coefficient and irradiance reflectance could be determined. Furthermore, the inherent optical properties (IOPs) absorption and backscattering were derived through inversion of these parameters with previously published relationships obtained from radiative transfer model simulations. However, particulate backscattering coefficients $b_{b p}$, obtained by subtracting the backscattering coefficients by seawater $b_{b s w}$ from total backscattering coefficients $b_{b t}$ derived from the inversion, could not be reliably estimated because the noise inherent to the inversion method combined with the uncertainty of the reflectance determinations was on the order of $10^{-3} \mathrm{~m}^{-1}$. Total backscattering values lower than this level in the visible also test our present knowledge of pure seawater scattering coefficients (Morel et al., 2007). The aim of the work described herein is to present measured backscattering and other IOPs from these same waters, in an effort to enhance our understanding of properties that the reflectance inversions of Morel et al. (2007) were not able to fully resolve. By paying careful attention to calibration, measurement, and processing protocols, increasing detector gains for the backscattering sensor, and averaging multiple samples, backscattering uncertainties on the order of $10^{-5} \mathrm{~m}^{-1}$ were achieved.

Spectral backscattering is a key parameter influencing the reflectance properties of the ocean (see reviews by Stramski et al., 2004; Twardowski et al., 2005; Zaneveld et al., 2005). It largely controls the Bidirectional Reflectance Distribution Function (BRDF) that describes how a downwelling radiance field is translated into an upwelling radiance field. Backscattering is thus of central importance in the remote sensing of the ocean using passive (i.e. solar source) and active (i.e. artificial source) methods. The specific magnitude of backscattering is particularly important for those algorithms that do not rely on spectral ratios of reflectance or water-leaving radiance, such as the current experimental algorithm for calcite (Balch et al., 2005).

The dominant sources of backscattering in the ocean are scattering by the particle population and the molecular scattering by pure seawater. Dissolved materials besides salts ("truly" dissolved in this case, i.e. not including colloids $<0.2 \mu \mathrm{m})$ are not expected to impart any significant scattering to natural seawater (Shifrin, 1988). Positive correlations have been demonstrated between backscattering by particles, particle concentration and particulate organic carbon (Balch et al., 1999; Stramski et al., 1999), and the particulate backscattering to scattering ratio $\left(b_{b p} / b_{p}\right)$ has been shown to be an indicator of bulk particle refractive index, a parameter closely related to particle density (Twardowski et al., 2001; Boss et al., 2004; Sullivan et al., 2005; Loisel et al., 2007). Despite progress, however, understanding specific sources of particulate backscattering in the ocean, crucial for interpretation through inversion, is confounded by a rudimentary understanding of the effects of particle nonsphericity and heterogeneous composition (although recent contributions are encouraging; see Clavano et al., 2007 and Gordon, 2006, 2007). The controversial nature of particulate backscattering lends further motivation to our efforts to obtain wellcharacterized, accurate data with well-defined uncertainties, a requirement before any productive discussion of its origins or a scattering budget may be attempted.

While particulate backscattering typically dominates in coastal waters, molecular backscattering by seawater becomes very significant in oceanic waters (Shifrin, 1988; Morel and Gentili, 1991). Backscattering by seawater is typically considered a "known" in remote sensing and biogeochemical algorithms (Stramski et al., 2004; Twardowski et al., 2005), but a thorough assessment of the accuracy of available values has not been carried out. Considering estimates of pure water and seawater scattering from Morel (1974), Shifrin (1988), and Buiteveld et al. (1994), one could argue that a reasonable uncertainty in scattering by seawater may be greater than $10 \%$. In the extremely clear waters of the South Pacific, this uncertainty has a substantial $(50 \%$ or more) impact on estimating particulate backscattering because backscattering by the dominant pure seawater component must be subtracted from direct measurements of total backscattering. Such data may thus provide a valuable means to test the current seawater values available in the literature.

Routine field measurement of the backscattering coefficient has been possible with commercially available instrumentation since the late 1990's (Maffione and Dana, 1997; Moore et al., 2000; Twardowski et al., 2005). Despite employing different calibration methods, different optical configurations, and different processing algorithms, different sensors have previously been found to agree within about 10\% (Pegau et al., 2001; Prentice et al., 2002; Boss et al., 2004) and more recently within $3 \%$ in data from very clear Crater Lake, Oregon, USA (Boss et al., 2007). The lowest backscattering values reported in the literature, to our knowledge, were measured in Crater Lake by Boss et al. (2007) and Stramska and Stramski (2005) in the Greenland Sea, where $b_{b p}$ in the mid-visible reached values on the order of $10^{-4} \mathrm{~m}^{-1}$.

Distributions of backscattering are presented along a transect through the central South Pacific gyre collected during the Biogeochemistry and Optics South Pacific Experiment (BIOSOPE) cruise aboard the R/V L'Atalante. Our primary objective was to resolve biogeochemical processes occurring in the South Pacific using high sampling rate, profiling optical instrumentation as effective proxies, but a fundamental 
first step in this endeavor is determining to what extent the measurements of backscattering and other IOPs are accurate in these extremely clear waters. Future work will delve more thoroughly into analytical and semi-analytical associations between scattering and the underlying particle biogeochemistry.

\section{Study site}

The South Pacific anticyclonic gyre is characterized as systematically hyperoligotrophic, with chlorophyll concentrations reaching as low as $0.02 \mathrm{mg} \mathrm{m}^{-3}$ at the surface (Morel et al., 2007; Claustre et al., 2007 ${ }^{1}$ ). The BIOSOPE cruise occurred in October-December 2004 and consisted of a transect $\sim 8000 \mathrm{~km}$ long from the sub-Equatorial waters near the Marquesas Islands, to Easter Island in the central gyre, to the Chilean upwelling region. Only those measurements collected at stations in the central gyre are considered here (Fig. 1). Deep chlorophyll maxima and euphotic zone depths were typically observed between $160-210 \mathrm{~m}$ in this region. For details of the hydrography and the physics of this region, see Claustre et al. (2007) ${ }^{1}$.

\section{Review of molecular scattering by pure seawater}

Past theory and measurements of the volume scattering function and total scattering coefficient by pure seawater, $\beta_{s w}(\theta) \mathrm{m}^{-1} \mathrm{sr}^{-1}$ and $b_{s w} \mathrm{~m}^{-1}$, respectively, are reviewed here because of their importance, particularly with respect to backscattering, in clear ocean waters. Pure seawater scattering is typically considered to be small and the common practice is to adopt a certain standard, which is not expected to vary for different environmental conditions of seawater. In terms of total scattering, pure water may contribute up to $10 \%$ in the visible for very clear ocean waters, so that this practice is usually not fraught with substantial error. Pure seawater scattering has a much more significant effect in the backward direction, however, owing to the nearly isotropic nature of molecular scattering by water and the strongly forward-peaked characteristic of volume scattering functions of natural particle populations. This results in typically $<1 \%$ of particulate scattering in the open ocean occurring in the backward direction (except for unusual cases such as coccolithorphorid blooms), as opposed to $50 \%$ of pure seawater scattering. The contributions of seawater and particles to total backscattering are thus comparable in many open ocean waters, and, in the clearest waters, seawater backscattering, $b_{b s w} \mathrm{~m}^{-1}$, readily exceeds an $80 \%$ contribution (Shifrin, 1988; Morel and Gentili, 1991). An accurate estimation of $b_{b s w}$ becomes critical when one wishes to isolate particulate

\footnotetext{
${ }^{1}$ Claustre, H., Sciandra, A., and Vaulot, D.: Introduction to the special section : bio-optical and biogeochemical conditions in the South East Pacific in late 2004 - the BIOSOPE cruise, Biogeosci. Discuss., in preparation, 2007.
}

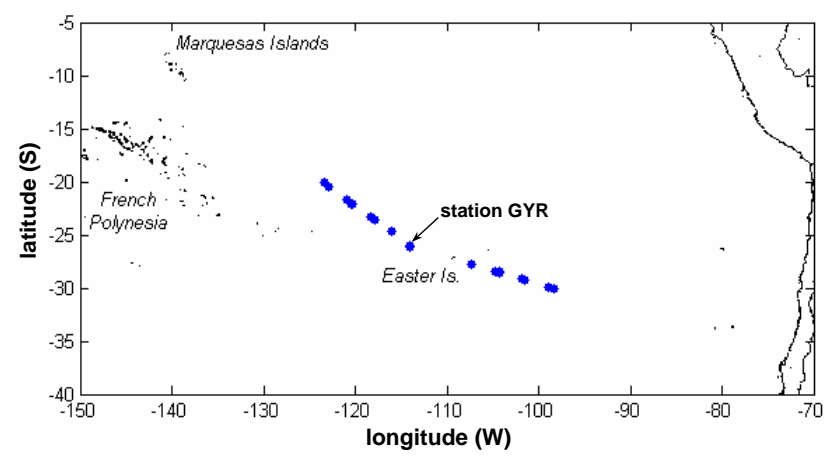

Fig. 1. Map of study region in the Southeast Pacific. Locations are marked in blue for all stations sampled in the very clear central gyre. The station labeled GYR at $114^{\circ} \mathrm{W}$ longitude was the location of a $4 \mathrm{~d}$ time series of measurements.

backscattering from measurements of total backscattering. This is true for any open ocean waters, not only the extremely clear waters addressed in this study.

There are three independent estimates of pure water scattering that may be considered among the most accurate to date; these are found in Morel (1974), Shifrin (1988), and Buiteveld et al. (1994). All three use the same equations from Einstein-Smoluchowski theory, which describes scattering resulting from density and temperature fluctuations in media (Morel, 1974 and Shifrin, 1988 both have excellent reviews). Where the estimates differ is in the physical expressions, mostly derived from empiricism, used as inputs to the equations. For the sake of clarity, the equations are reproduced:

$\beta_{w}\left(90^{\circ}\right)=\frac{2 \pi^{2}}{\lambda^{4} B_{T}} k T_{a} n^{2}\left(\frac{\partial n}{\partial P}\right)_{T}^{2} C$,

where the Cabannes factor $C=\frac{(6+6 \delta)}{(6-7 \delta)}$, accounts for the anisotropy of water due to fluctuations in molecule orientation. The parameter $\delta$ is the depolarization ratio. The volume scattering function is computed from:

$\beta_{w}(\theta)=\beta_{w}\left(90^{\circ}\right)\left[1+p\left(90^{\circ}\right) \cos ^{2}(\theta)\right]$,

where the degree of polarization at 90 degrees, $p\left(90^{\circ}\right)$, is $\frac{(1-\delta)}{(1+\delta)}$. Total scattering is then obtained from:

$b_{w}=\frac{16 \pi}{3} \beta_{w}\left(90^{\circ}\right)\left[\frac{1}{2} \frac{(2+\delta)}{(1+\delta)}\right]$.

Removing the effect of anisotropy in Eq. (2), i.e., letting $\delta=0$ so that $p\left(90^{\circ}\right)=1$, results in the classic Rayleigh scattering angular pattern. Notation for the parameters in Eq. (1) is provided in Table 1 along with the expressions adopted by Buiteveld et al. (1994).

The four experimental variable inputs to Eq. (1) are $B_{T}(T, S), n(\lambda, T, S, P),(\partial n / \partial P)_{T}(\lambda, T)$, and $\delta$. Where it can be determined, each of the three studies mentioned 
Table 1. Notation

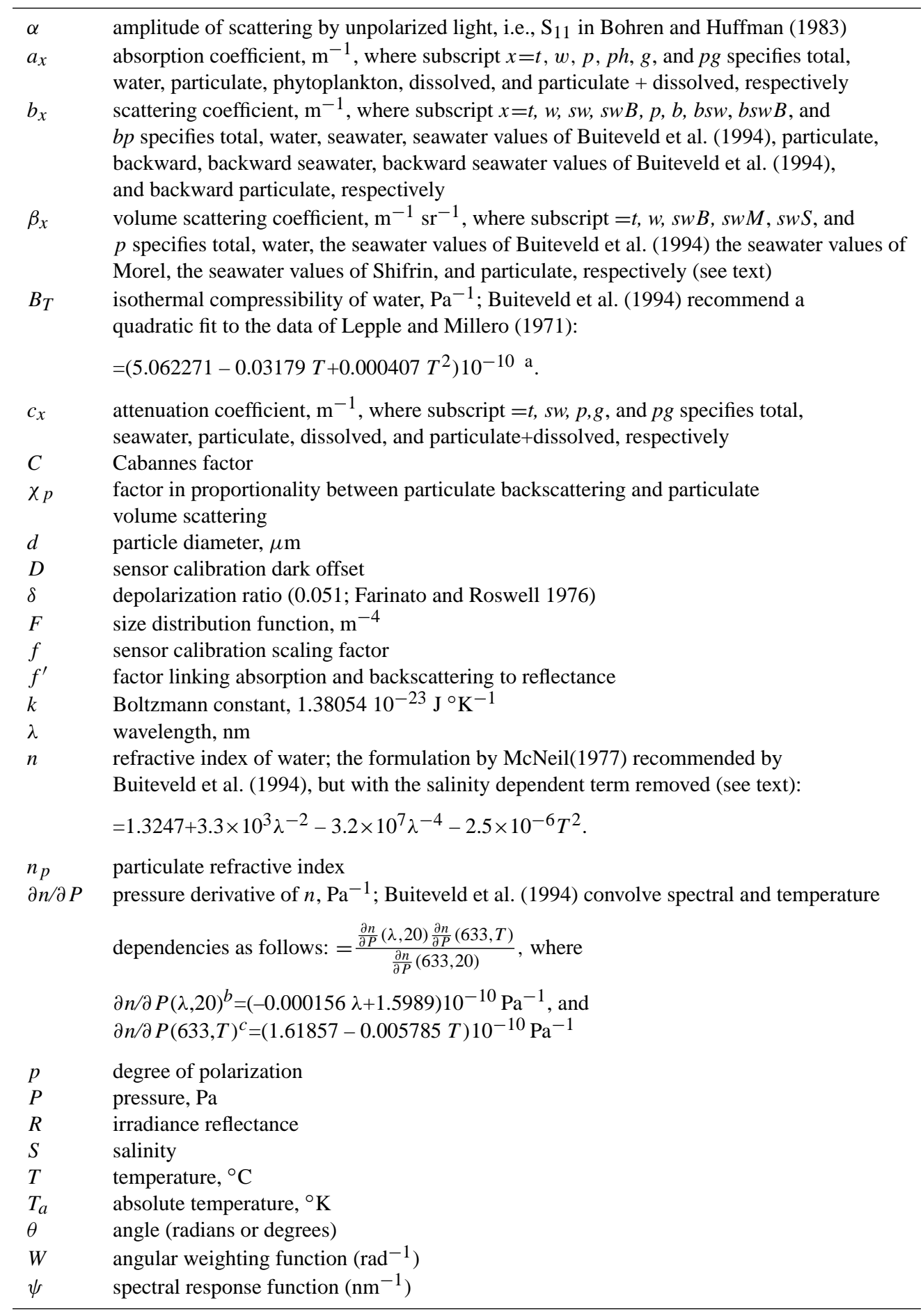

${ }^{\text {a }}$ Factor reported as $10^{-11}$ in Buiteveld et al. (1994).

b O'Conner and Schlupf (1967)

c Evtyushenkov and Kiyachenko (1982) 
uses different expressions for these parameters, except both Shifrin (1988) and Morel (1974) use the same $\delta$ value of 0.09 . Without belaboring the details of the precise differences in the parameters where it is possible to directly compare, a general summarization may be reached that the expressions compiled by Buiteveld et al. (1994) appear to be the most current in the literature (or are at least very close), as might be expected since their work is the most recent. In particular, Buiteveld et al. (1994) use a $\delta$ value of 0.051 based on the work of Farinato and Roswell (1976), who claim that the much higher values previously found in the literature were the result of stray light contamination and photometer geometry errors. Their newer values were also closer to a theoretical estimate. The Buiteveld et al. (1994) values were thus adopted here, unless specifically noted otherwise. This decision will be evaluated later.

Because all of the physical expressions entering into Eq. (1) are not provided in Morel (1974) and Shifrin (1988), it is desirable to fit a suitable model to their data to extrapolate results to fine spectral resolution (the values of Buiteveld et al. (1994) may be computed directly for any $\lambda$ and $T$. The following relationships are constructed for $T=20^{\circ} \mathrm{C}$ at atmospheric pressure:

Morel $: b_{w}=3.50\left(\frac{\lambda}{450}\right)^{-4.32} 10^{-3} \mathrm{~m}^{-1}$, and

Shifrin : $b_{w}=1.49\left(\frac{\lambda}{546}\right)^{-4.17} 10^{-3} \mathrm{~m}^{-1}$.

In both cases, the amplitude values $\left(b_{w}(450)=3.50 \times 10^{-3} \mathrm{~m}^{-1}\right.$ and $\left.b_{w}(546)=1.49 \times 10^{-3} \mathrm{~m}^{-1}\right)$ were provided in Tables from the original texts. The 4.32 exponent of the model used in Eq. (4) was obtained with a nonlinear hyperbolic fit $\left(R^{2}=0.99\right)$ to the $25-\mathrm{nm}$ spaced data provided in Table 4 of Morel using only the data from 350 to $525 \mathrm{~nm}$. This value matches Morel's recommended slope of 4.32. Acceptable accuracies $(<0.5 \%)$ between the Eq. (4) model and Morel's calculated data are only observed in the 350 to $525 \mathrm{~nm}$ spectral range (Table 2). The 4.17 slope used in Eq. (5) was provided on p. 82 of Shifrin (1988). For comparison, the slope for calculations using the Buiteveld et al. (1994) expressions is 4.14. This slope varies negligibly with temperature. The models in Eqs. (4) and (5) are transferable to $\beta_{w}(\lambda, \theta)$ using Eqs. (2) and (3):

Morel : $\beta_{w}(\lambda, \theta)=2.18\left(\frac{\lambda}{450}\right)^{-4.32}$

$\left[1+p(90) \cos ^{2}(\theta)\right] 10^{-4} \mathrm{~m}^{-1} \mathrm{sr}^{-1}$, and

Shifrin : $\beta_{w}(\lambda, \theta)=0.93\left(\frac{\lambda}{546}\right)^{-4.17}$

$\left[1+p(90) \cos ^{2}(\theta)\right] 10^{-4} \mathrm{~m}^{-1} \mathrm{sr}^{-1}$

Equation (6) is also only strictly applicable between 350 and $525 \mathrm{~nm}$.

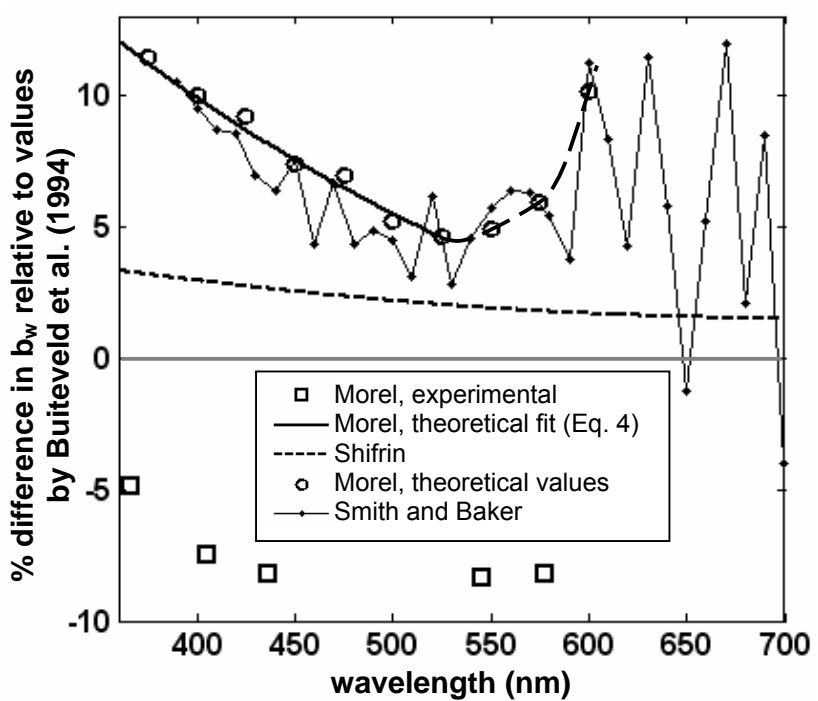

Fig. 2. Comparison of pure water scattering $\mathrm{b}_{w}$ from Buiteveld et al. (1994), Morel (1968, 1974), and Shifrin (1988). Percent differences relative to the values of Buiteveld et al. (1994) are plotted. The gray line demarcates zero. Equation (5) is used for Shifrin's values. Circles represent the theoretical values of Morel (1974). Equation (4) is used to approximate Morel's theoretical values for wavelengths shorter than $525 \mathrm{~nm}$ (solid black curve; long dashes approximately extend relationship through Morel's theoretical values at 550, 575, and $600 \mathrm{~nm}$; see Table 2). The experimental values of $\beta_{w}\left(90^{\circ}\right)$ reported in Morel (1968) are converted to $\mathrm{b}_{w}$ using Eq. (3) and $\delta=0.09$. Note that a $\delta$ of 0.051 would increase these experimental values by $\sim 2 \%$. The values of Smith and Baker (1981), derived directly from Morel (1974), tend to exhibit more noise because their Table 1 is truncated at 4 decimal places.

Table 2 provides $b_{w}$ estimates from the various sources with the same wavelength range and resolution of Morel (1974). Shifrin's and Morel's $b_{w}(\lambda)$ values relative to those of Buiteveld et al. (1994) are plotted in Fig. 2. It can be seen that Shifrin's values are between 1-3\% higher throughout the visible and Morel's values range from about 5\% higher in the green to $\sim 10 \%$ higher in the short blue and near-red. The disagreement between Morel's values and those of Buiteveld et al. (1994) observed in the near-red contradicts statements in Buiteveld et al. (1994). Buiteveld et al. (1994) estimate the accuracy of their pure water scattering values at $\pm 6 \%$. Morel (1974) noted that the depolarization ratio has a significant influence on theoretical scattering values. Interestingly, if a $\delta$ value of 0.09 is used in the Buiteveld et al. (1994) expressions, their scattering values increase by $\sim 7 \%$ (independent of $\lambda$ ). Similarly, the values of Morel (1974) and Shifrin (1988) would decrease by $\sim 7 \%$ if a $\delta$ value of 0.051 is substituted. Thus, if Morel and Buiteveld et al. (1994) used the same $\delta$, the resulting agreement would improve significantly ( $\pm 3 \%$ throughout the visible). Since Shifrin's values are already relatively close to Buiteveld's, the effect of the higher $\delta$ value used by Shifrin was compensated to a degree in the 
Table 2. Pure water scattering parameters.

\begin{tabular}{|c|c|c|c|c|c|c|c|c|c|c|c|}
\hline \multirow[b]{2}{*}{ parameter } & \multicolumn{11}{|c|}{$\lambda(\mathrm{nm})$} \\
\hline & 350 & 375 & 400 & 425 & 450 & 475 & 500 & 525 & 550 & 575 & 600 \\
\hline $\begin{array}{l}\beta_{w}\left(90^{\circ}\right) \quad\left(10^{-4} \mathrm{~m}^{-1} \mathrm{sr}^{-1}\right) \\
\text { from Morel }(1974)^{\mathrm{a}}\end{array}$ & 6.47 & 4.80 & 3.63 & 2.80 & 2.18 & 1.73 & 1.38 & 1.12 & 0.93 & 0.78 & 0.68 \\
\hline $\begin{array}{l}\mathrm{b}_{w} \mathrm{~b}_{\left(10^{-4} \mathrm{~m}^{-1}\right)} \\
\text { from Morel (1974) (1) }\end{array}$ & 103.9 & 77.1 & 58.3 & 45.0 & 35.0 & 27.8 & 22.2 & 18.0 & 14.9 & 12.5 & 10.9 \\
\hline $\begin{array}{l}\mathrm{b}_{w}\left(10^{-4} \mathrm{~m}^{-1}\right) \\
\text { modeled from Eq. (4) (2) }\end{array}$ & 103.7 & 76.9 & 58.2 & 44.8 & 35.0 & 27.7 & 22.2 & 18.0 & 14.7 & 12.1 & 10.1 \\
\hline$\%$ difference ( 1 and 2 ) & 0.25 & 0.20 & 0.14 & 0.37 & 0.03 & 0.27 & -0.18 & 0.02 & 1.52 & 3.10 & 7.51 \\
\hline $\begin{array}{l}\mathrm{b}_{w}{ }^{\mathrm{c}}\left(10^{-4} \mathrm{~m}^{-1}\right) \\
\text { from Buiteveld } \\
\text { et al. (1994) }\end{array}$ & 92.0 & 69.2 & 53.0 & 41.2 & 32.6 & 26.0 & 21.1 & 17.2 & 14.2 & 11.8 & 9.9 \\
\hline $\begin{array}{l}\mathrm{b}_{w}{ }^{\mathrm{c}}\left(10^{-4} \mathrm{~m}^{-1}\right) \\
\text { from Shifrin (Eq. 5) }\end{array}$ & 95.2 & 71.4 & 54.5 & 42.4 & 33.4 & 26.6 & 21.5 & 17.5 & 14.5 & 12.0 & 10.1 \\
\hline
\end{tabular}

a Line 1 in Table 4 of Morel (1974).

${ }^{\mathrm{b}}$ Computed from $\beta_{w}\left(90^{\circ}\right)$ in Line 1 using Eq. (3) and $\delta=0.09$, i.e., $\mathrm{b}_{w M}=16.06^{*} \beta_{w}\left(90^{\circ}\right)$

c Computed at $20^{\circ} \mathrm{C}$.

expressions used for other physical parameters. Incidentally, Shifrin (1988) additionally determined pressure dependencies for pure water scattering, but the maximum effect down to $500 \mathrm{~m}$ (the domain of measurements in the work herein) was $1 \times 10^{-5} \mathrm{~m}^{-1}$, negligible with respect to our measurement uncertainties.

In addition to these theoretical estimates, Morel (1966, 1968) also determined $\beta_{w}\left(90^{\circ}\right)$ experimentally at five wavelengths, from which $b_{w}$ may be computed via Eq. (3) (Fig. 2). The measurements of Morel (1966) were made relative to optically pure benzene, which were converted to absolute values of $\beta_{w}\left(90^{\circ}\right)$ in the 1968 study, once a consensus on the absolute values for benzene was reached in the literature. Values of $b_{w}$ computed from the experimental $\beta_{w}\left(90^{\circ}\right)$ using a $\delta$ of 0.09 range between about 5-8\% lower than the values of Buiteveld et al. (1994) (Fig. 2). Using a $\delta$ value of 0.051 , the values range between $3-6 \%$ lower. Thus, we may conclude that if the same $\delta$ value of 0.051 that was used in Buiteveld et al. (1994) is used in computing $b_{w}$ for both Morel's theoretical and experimental data, the results agree with the Buiteveld et al. (1994) theoretical values within their reported accuracy.

The effects of sea salts on pure water scattering are substantial. Sea salts alter the scattering behavior of pure water rather than imparting additional molecular scattering (Shifrin, 1988). Morel (1966, 1968, 1974) determined that dissolving sea salts to a salinity of 35-39 increases scattering by approximately $30 \%$. This relationship was based on measurements in a purified natural seawater sample collected from the Mediterranean, and supported by theoretical extrapolations of results from measurements in artificial seawater and purified $\mathrm{NaCl}$ solutions. This is a very valuable data point because, to our knowledge, there are currently no other measurements of this substantial effect in the literature. In the very clear waters of the central gyre, a $5 \%$ uncertainty in this estimate of $30 \%$ enhancement can translate into a $50 \%$ uncertainty in some $b_{b p}$ estimates. Moreover, efforts to measure $b_{b p}$ in any open ocean environment will be appreciably influenced by the accuracy of this salt effect estimate. This is clearly an area where additional experimentation could be of benefit. Such experiments are extraordinarily difficult to carry out, however, because of the effects of particle contamination in the sample.

We presume linearity with respect to salinity based on theoretical predictions (Shifrin, 1988) and experimental results summarized by Morel (1974) to derive a salinity adjustment of [1+0.3S/37] based on Morel's work. This term is multiplied by $b_{w}$ and $\beta_{w}(\lambda, \theta)$ obtained using the expressions of Buiteveld et al. (1994) to obtain $b_{s w B}$ and $\beta_{s w B}(\lambda, \theta)$, respectively. We consider these values to be the best estimates of pure seawater scattering. MATLAB code to compute these coefficients can be downloaded from: http:/wetlabs.com/ appnotes/scatteringcalcstwardo.pdf. These values, or values very close ( $<2 \%$ difference), have previously been used by Sullivan et al. (2006) and are provided in Morel et al. (2007). Because Morel's 30\% enhancement for seawater was an empirical observation relative to pure water, we do not include the dependency of salinity in the seawater refractive index term (see Table 1). Thus, for seawater, scattering by analogous pure water at a given $\lambda$ and $\mathrm{T}$ is computed, and then the entire salinity effect is assumed accounted for in the adjustment from Morel. 
Equation (6) multiplied by the $[1+0.3 \mathrm{~S} / 37]$ salinity term results in $\beta_{s w M}(\lambda, \theta)$. Similarly, $\beta_{s w S}(\lambda, \theta)$ are derived from multiplying Eq. (7) by the salinity adjustment term. It should be noted that in Tables of $b_{s w}(546)$ in Chapt. 3 of Shifrin (1988), the final adjustment for salinity relative to pure water is significantly greater (5-9\% higher) than values predicted using the [1+0.3S/37] relationship here, even though Morel's work is cited. Thus, our estimated $\beta_{s w S}(\lambda, \theta)$ here would not appear to agree with Shifrin's own seawater values (there are no $\beta_{s w}$ values provided in Shifrin, but they can be derived from Eqs. (2) and (3) knowing $b_{s w}$ ).

For the volume scattering function of pure seawater, the $\beta_{s w M}(\lambda, \theta)$ values (or values derived from a very similar model) have typically been adopted as the standard in the literature. For $b_{s w}(\lambda)$, the modeled values of Morel (1974) or the interpolation of these values carried out by Smith and Baker (1981) are typically used.

Pure seawater scattering was halved to obtain pure seawater backscattering. For the computations of pure seawater scattering, in-situ measured temperature (applied in the Buiteveld et al. (1994) expressions, see Table 1) and salinity for each depth bin were applied. It is important to note that the total variations in pure water backscattering as a function of the temperature and salinity ranges sampled were significant with respect to resulting particulate backscattering magnitudes (see below), typically up to $1 \times 10^{-4} \mathrm{~m}^{-1}$ at $532 \mathrm{~nm}$ over a $500 \mathrm{~m}$ profile.

\section{Instrumentation and methods}

\subsection{Absorption and attenuation coefficients}

In-situ measurements of hydrographic and optical parameters were made with a ship deployed profiling package. Conductivity, temperature, and depth parameters were measured with a SeaBird Electronics 9/11+CTD. Absorption coefficients and beam attenuation coefficients for all the inwater constituents except water, $a_{p g}(\lambda)=a_{p}(\lambda)+a_{g}(\lambda)$ and $c_{p g}(\lambda)=c_{p}(\lambda)+a_{g}(\lambda)$, were measured with an ac-9 (WET Labs), where $a_{p}$ and $c_{p}$ are particulate absorption and attenuation, respectively, and $a_{g}$ is the absorption coefficient for the dissolved fraction. The ac-9 has dual, 25-cm flow cells in which spectral absorption and attenuation are measured at nine wavelengths in the visible and near-IR with a sampling rate of approximately $6 \mathrm{~Hz}$. The acceptance angle for the attenuation measurement is $0.93^{\circ}$. A second ac9 was used to measure $a_{g}(\lambda)$ by fitting a $0.2 \mu \mathrm{m}$ pleated, maxi-capsule filter (Gelman) to the intake of the absorption channel. The parameter $c_{p}(\lambda)$ was then derived from $c_{p g}(\lambda)$ $a_{g}(\lambda)$, and $b_{p}(\lambda)$, the particulate scattering coefficient, was derived from $c_{p g}(\lambda)-a_{p g}(\lambda)$. Estimates of phytoplankton absorption at $676 \mathrm{~nm}, a_{p h}(676)$, were made using the baseline subtraction method (Davis et al., 1997). Total absorption, $a_{t}$, was computed by adding the pure water absorption values of Pope and Fry (1997).

Details of the method for ac- 9 calibration, field use, and the application of corrections for temperature, salinity, scattering error, and time lags are described in Twardowski et al. (1999). Coefficients for correcting the effects of temperature and salinity on pure water absorption and attenuation recently derived by Sullivan et al. (2006) were applied. The ac-9s were calibrated to better than $0.002 \mathrm{~m}^{-1}$ replicability at all channels before and after the cruise by passing optically clean, bubble-free water (Barnstead, 4-cartridge Nanopure system) through the flow cells. These calibrations effectively serve as water blanks for the in-situ measurements. Note this method removes the effects of molecular scattering by pure water from the ac- 9 measurements, but that the salt enhancement effect remains. This residual salt effect is on the order of $10^{-4}$ throughout the visible, however, and could be ignored. The Zaneveld et al. (1994) proportional method was used to correct the scattering error in the absorption measurements, where the signal at $715 \mathrm{~nm}$, after temperature and salinity corrections, is assumed to consist entirely of the scattering error, and is then scaled through the visible according to the spectral dependence of measured $c_{p g}(\lambda)-a_{p g}(\lambda)$. After all corrections, ac- 9 data were averaged to $1 \mathrm{~m}$ bins.

Finer temporal resolution of drifts in the ac-9 used for $a_{g}$ measurements during the cruise was achieved by crosscalibration to high-sensitivity capillary waveguide spectrophotometric measurements of $a_{g}$ made on discrete samples from $250 \mathrm{~m}$ by Bricaud et al. $(2007)^{2}$. The waveguide pathlength was $2 \mathrm{~m}$ with a blank consisting of clean (preashed) salt dissolved in purified water and passed through a $0.2 \mu \mathrm{m}$ filter. Samples from $250 \mathrm{~m}$ were chosen because of the excellent consistency in $a_{g}$ at this depth throughout the cruise (worst case standard deviation of all wavelengths was $0.0036 \mathrm{~m}^{-1}$ at $\mathrm{a}_{g}(412), \mathrm{N}=9$ ) and because the temperature profile was relatively homogeneous in this depth range, minimizing variability from ac-9 internal temperature corrections (Twardowski et al., 1999). Drift corrections were obtained by simple subtraction and were linearly extrapolated over the time period of the cruise to obtain corrections for casts without discrete sample $a_{g}$ measurements. The total deviation in final corrected drifts through the period sampled was typically on the order of 0.001 to $0.002 \mathrm{~m}^{-1}$.

For the ac- 9 used primarily for $a_{p g}$ and $c_{p g}$ measurements, drift corrections were anchored at a station in the gyre where consecutive casts were made with and without a $0.2 \mu \mathrm{m}$ prefilter. Measurements in the dissolved fraction could then be subtracted from successive measurements of the combined dissolved and particulate material, providing $a_{p}$ and $c_{p}$ spectra that were the most accurate of any optical measurement that were made with the ac-9s because any uncertainties

\footnotetext{
${ }^{2}$ Bricaud, A., Babin, M., Claustre, H., Ras, J., and Tieche, F.: The partitioning of light absorption in South Pacific waters, Biogeosciences Discuss., in preparation, 2007.
} 
in calibration drifts cancel (temperature and salinity relationships verified consistent water types between the consecutive casts). Resulting $a_{p}$ spectra at $250 \mathrm{~m}$ were compared to particulate absorption determined independently on a discrete sample with the filter pad spectrophotometric technique (Bricaud and Stramski, 1990), with agreement better than $0.001 \mathrm{~m}^{-1}$ at all wavelengths except $412 \mathrm{~nm}$, where the agreement was $0.0035 \mathrm{~m}^{-1}$. A further evaluation of the filter pad $a_{p}$ measurements on samples collected at $250 \mathrm{~m}$ throughout the central gyre demonstrated excellent consistency (worst case standard deviation of $0.0018 \mathrm{~m}^{-1}$ at $412 \mathrm{~nm}, \mathrm{~N}=8$ ). All $a_{p}$ and $c_{p}$ values at $250 \mathrm{~m}$ were thus set to the values determined at the central gyre station and the corrected $a_{g}$ measurements were then added in to obtain the final $a_{p g}$ and $c_{p g}$ values at $250 \mathrm{~m}$, from which final drift corrections were determined and linearly extrapolated to all stations.

Uncertainties in the final ac-9 IOPs are comprised of both random noise error as well as bias error. The former is $<0.001 \mathrm{~m}^{-1}$ at all wavelengths, which was reduced further by depth binning. Based on the above procedures, worst case bias errors for the final $a_{g}, a_{p g}, c_{p g}$, and derived $a_{p}, c_{p}$, and $b_{p}$ are estimated at $0.002 \mathrm{~m}^{-1}, 0.003 \mathrm{~m}^{-1}$, $0.003 \mathrm{~m}^{-1}, 0.003 \mathrm{~m}^{-1}, 0.003 \mathrm{~m}^{-1}$, and $0.004 \mathrm{~m}^{-1}$, respectively. Throughout the cruise, several casts were also collected with either both ac-9s filtered or unfiltered, allowing direct intercomparisons for validation, with agreement at or below these uncertainties.

\subsection{Volume scattering and backscattering coefficients}

An ECO-BB3 (WET Labs) was used to measure $117^{\circ}$ scattering, $\beta_{t}\left(117^{\circ}\right) \mathrm{m}^{-1} \mathrm{sr}^{-1}$, at 462,532 , and $650 \mathrm{~nm}$ at a sampling rate of $1 \mathrm{~Hz}$. These measurements are synchronized at $60 \mathrm{~Hz}$ to reject ambient light and any inelastic scattering associated with excitation from one of the other sources (however, it is not impossible that inelastic scattering may be excited and detected within a source-detector pair). Before the field deployments, sensor gains were increased in an effort to better resolve very low scattering. The sensor was calibrated at the factory with $2 \mu \mathrm{m}$ microspherical polystyrene beads (Duke Scientific) using established protocols to derive a scaling factor $f$ and dark offset $D$ for each of the three measurements (Moore et al., 2000). Calibrated $\beta_{t}\left(117^{\circ}\right)$ values are obtained by subtracting $D$ from the raw digital counts and then multiplying by $f$. Supplied values of $f$ (specific for this instrument) were $2.386 \times 10^{-5}$, $1.015 \times 10^{-5}$, and $3.781 \times 10^{-6} \mathrm{~m}^{-1} \mathrm{sr}^{-1}$ counts $^{-1}$ for the 462,532 , and $650 \mathrm{~nm}$ measurements, respectively. In this work, $D$ values were determined directly in the field by covering the detector only with black electrical tape (using care not to cover any of the source window or leave any of the detector window exposed). This is the most accurate method of $D$ determination since the specific environmental conditions during deployment are taken into account. Vertical pro- files of dark offsets down to $500 \mathrm{~m}$ were constant within the standard deviation of the electronic noise for all three channels. Thus, for each $D$, the entire profile was averaged and these values $(49.9,53.8$, and 59.8 raw counts for measurements at 462,532 , and $650 \mathrm{~nm}$, respectively) were used along with the factory derived $f$ parameters in processing. Drift in the ECO-BB3 calibration parameters over the course of the cruise are assumed negligible. Limited attempts to quantify drifts in ECO sensors in the past have not found any appreciable drift beyond experimental errors over periods of months, although, to our knowledge, a rigorous analysis has not been carried out.

Backscattering coefficients, $b_{b p}(\lambda)$, were derived for each spectral $\beta_{t}\left(117^{\circ}\right)$ using the method described in Sullivan et al. (2005). Briefly, $\beta_{s w B}\left(\lambda, 117^{\circ}\right)$ (see Sect. 2) were subtracted from measured $\beta_{t}\left(\lambda, 117^{\circ}\right)$ to obtain $\beta_{p}\left(\lambda, 117^{\circ}\right)$, and then a $\chi_{p}$ factor was used in a proportionality to link $b_{b p}$ and $\beta_{p}$ (see Boss and Pegau 2001 and Boss et al., 2004):

$b_{b p}=2 \pi \chi_{p}\left(117^{\circ}\right) \beta_{p}\left(117^{\circ}\right)$.

Based on extensive measurements made in a wide diversity of water types by Sullivan et al. (2005), a value of 0.90 was found for $\chi_{p}\left(125^{\circ}\right)$. We assumed the $\chi_{p}\left(117^{\circ}\right)$ would not be significantly different and so the same value was adopted. The $\chi_{p}\left(117^{\circ}\right)$ parameter was assumed to be spectrally independent after Boss and Pegau (2001). Absorption of the incident and scattered beams (Moore et al., 2000) was corrected using ac-9 measurements, although because of the small effective pathlength $(\sim 3.9 \mathrm{~cm})$ and extreme clarity of the water, these corrections were negligible.

As with the ac-9 IOPs, uncertainties in the final $b_{b p}$ values are comprised of both random noise error as well as possible bias error. Unlike the ac-9, however, some possible bias errors (e.g., errors in determining $f$ ) scale with magnitude and are more accurately represented in terms of a $\%$ error. Electronic noise errors were $1.7 \times 10^{-5}, 4.4 \times 10^{-6}$, and $1.6 \times 10^{-6} \mathrm{~m}^{-1} \mathrm{sr}^{-1}$ for measurements at 462,532 , and $650 \mathrm{~nm}$, respectively. Depth bin averaging of just a few data points can reduce these errors by more than half. Errors associated with the determination of the $D$ parameters are assumed to be similar. There are two general errors possible with the $f$ parameters: (1) uncertainty in determining the experimental ratio of counts (measured with the ECO sensor) to $b_{p}$ (measured with an ac-9) during calibration with a series of suspensions of microspheres, and (2) bias errors in the theoretical estimation of the phase function $\left[\beta_{p}(\bar{\theta}, \bar{\lambda})\right.$ $\left./ b_{p}\right]$ for these microspheres (note that $f$ is determined by dividing the latter parameter by the former) (Moore et al., 2000). In evaluating the mean square error of experimental data from calibrations, the first source of uncertainty has been determined to be small, typically about $1 \%$.

The second source of uncertainty is more difficult to evaluate. Theoretical $\left[\beta_{p}(\bar{\theta}, \bar{\lambda}) / b_{p}\right]\left(\mathrm{sr}^{-1}\right)$ values specific for a given sensor are computed from Mie theory assuming a Gaussian size distribution model with the mean 
microsphere size and standard deviation reported by Duke Scientific. The normal dispersion refractive index equation for polystyrene suggested by Duke Scientific is used $\left(n_{p}=1.5663+0.00785 \lambda^{-2}+0.000334 \lambda^{-4}\right.$, with $\lambda$ in $\left.\mu \mathrm{m}\right)$. With full functionality expressed, $\left[\beta_{p}(\bar{\theta}, \bar{\lambda}) / b_{p}\right]$ is obtained as follows:

$$
\begin{aligned}
& \frac{\beta_{p}\left(\bar{\lambda}, \sigma_{\lambda}, \bar{\theta}, \Delta \theta, \bar{d}, \sigma_{d}\right)}{b_{p}\left(\bar{\lambda}, \sigma_{\lambda}, \bar{d}, \sigma_{d}\right)}= \\
& \int_{0}^{\pi} \int_{\bar{\lambda}-3 \sigma_{\lambda}}^{\bar{\lambda}+3 \sigma_{\lambda}} \int_{\bar{d}-3 \sigma_{d}}^{\bar{d}+3 \sigma_{d}} W(\theta, \bar{\theta}, \Delta \theta) \Psi\left(\lambda, \bar{\lambda}, \sigma_{\lambda}\right) \alpha\left(d, \lambda, n_{p}, \theta\right) F\left(d, \bar{d}, \sigma_{d}\right) d d d \lambda d \theta \\
& 2 \pi \int_{0}^{\pi} \int_{\bar{\lambda}-3 \sigma_{\lambda}}^{\bar{\lambda}+3 \sigma_{\lambda}} \int_{\bar{d}-3 \sigma_{d}}^{\bar{d}+3 \sigma_{d}} \sin (\theta) \Psi\left(\lambda, \bar{\lambda}, \sigma_{\lambda}\right) \alpha\left(d, \lambda, n_{p}, \theta\right) F\left(d, \bar{d}, \sigma_{d}\right) d d d \lambda d \theta
\end{aligned}
$$

Weighting functions $W$ for the scattering measurements, computed numerically from the optical geometry by J. R. V. Zaneveld (WET Labs), are isosceles triangles described by a centroid angle $\bar{\theta}$ and $\Delta \theta$, where the latter parameter is the baseline width of the function (Moore et al., 2000). Each of the ECO-BB3 measurements have identical $W$ defined by $\bar{\theta}=117^{\circ}$ and $\Delta \theta=36^{\circ}$. The spectral response of the sensor $\Psi$ is assumed Gaussian, defined by a centroid wavelength $\bar{\lambda}$ and standard deviation $\sigma_{\lambda}$. The spectral output of the LED source is convolved with the bandwidth of the detector interference filter to obtain $\Psi$ (the relative photodiode detector response within each spectral transmission window is assumed approximately constant). The parameter $\alpha$ is the amplitude of unpolarized light scattering by the microspheres computed from Mie theory and $F$ is the microsphere size distribution defined by a centroid $\bar{d}$ and standard deviation $\sigma_{d}$. Microspheres chosen by WET Labs for calibrations typically have a centroid $\bar{d}$ close to $2 \mu \mathrm{m}$. Reported size distributions have previously been verified in some bead samples using a Coulter Counter device, i.e., newly purchased beads purchased from Duke Scientific have consistently conformed to the reported distributions on the bottle. Volume scattering functions from these beads measured at one degree resolution with a bench top device have closely agreed with associated theoretical phase functions (M. Twardowski, unpubl. data), as other investigators have observed (Volten et al., 1997; Lee and Lewis, 2003; Slade and Boss, 2005). WET Labs calculations of $\left[\beta_{p}(\bar{\theta}, \bar{\lambda}) / b_{p}\right]$ have been independently verified within 1 to 2 percent by E. Boss (University of Maine, personal communication, 2005).

WET Labs normally disregards the spectral response term $\Psi(\lambda)$, as the effect is typically small $(<2 \%)$. The effect was specifically assessed here for the $462 \mathrm{~nm}$ measurement because of concern over a $34 \mathrm{~nm}$ spectral separation between the LED source, centered at $436 \mathrm{~nm}$, and the detector interference filter, centered at $470 \mathrm{~nm}$ (WET Labs currently employs a $\sim 466 \mathrm{~nm}$ LED source in this sensor). Convolving the LED spectral output with the interference filter bandwidth, the resulting spectral response exhibited a $\bar{\lambda}$ of $462 \mathrm{~nm}$, which was adopted for this measurement. The $\left[\beta_{p}(\bar{\theta}, \bar{\lambda}) / b_{p}\right]$ computed with this spectral response included was only $1.6 \%$ greater than the value originally used by WET

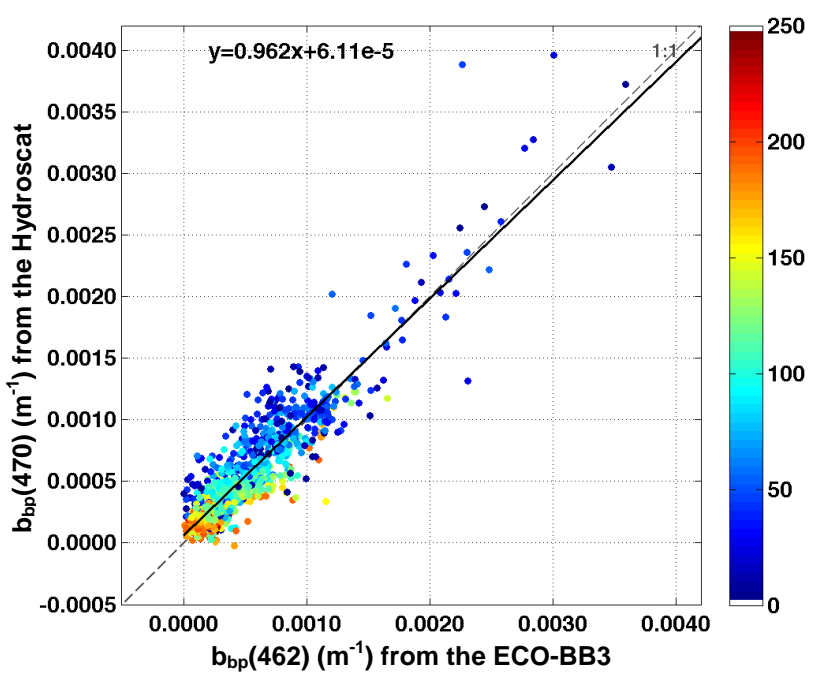

Fig. 3. Comparison of $b_{b p}(470)\left(\mathrm{m}^{-1}\right)$ data collected with a Hydroscat (HOBI Labs, Inc.) and $\mathrm{b}_{b p}(462)\left(\mathrm{m}^{-1}\right)$ from an ECO-BB3 (WET Labs, Inc.). Dotted line is 1:1 and the solid line is the linear least-squares regression. Data point color and associated colorbar represent sample depth $(\mathrm{m})$. Note that for this comparison, the pure seawater values $\beta_{s w M}\left(117^{\circ}\right)$ and $\beta_{s w M}\left(140^{\circ}\right)$ from Morel (1974) were used for the ECO-BB3 and Hydroscat, respectively.

Labs, although the $8 \mathrm{~nm}$ shift in $\bar{\lambda}$ significantly affects analyses because of the steeply sloped spectrum of pure seawater scattering. For 462,532 , and $650 \mathrm{~nm}, \sigma_{\lambda}$ values were 18,24 , and $14 \mathrm{~nm}$, respectively.

In total, the aggregate error from the computation in Eq. (9) is not readily amenable to "bottom up" estimation. An error of several percent may be possible based on indirect evidence of verifying sensor calibration with one bead by making measurements in solutions of other known beads, although errors accumulate from both the calibration and validation aspects in such a comparison. In cross-calibrations of many ECO scattering sensors (Sullivan et al., 2005), agreement has been consistently observed at the $<5 \%$ level, which at least demonstrates that if there are bias errors associated with, for example, imprecise size distributions, these errors are very consistent.

Taken as a whole, above mentioned errors in $\beta_{t}\left(117^{\circ}\right)$ that are independent of magnitude are estimated at $2 \times 10^{-5}$, $5 \times 10^{-6}$, and $2 \times 10^{-6} \mathrm{~m}^{-1} \mathrm{sr}^{-1}$ for measurements at 462 , 532 , and $650 \mathrm{~nm}$, respectively, after $1 \mathrm{~m}$ bin averaging. The aggregate error scaling with magnitude, the largest component determining accuracy in waters with higher particle loads, may be anywhere from a few percent to perhaps as large as $\sim 10 \%$, within the level of agreement others have previously found between sensors made by different manufacturers (Pegau et al., 2001; Prentice et al., 2002; Boss et al., 2004). Uncertainties in subsequently derived properties such as particulate volume scattering and particulate backscattering will be highly dependent on the accuracy of pure seawater $\beta_{s w}\left(117^{\circ}\right)$ estimates. 


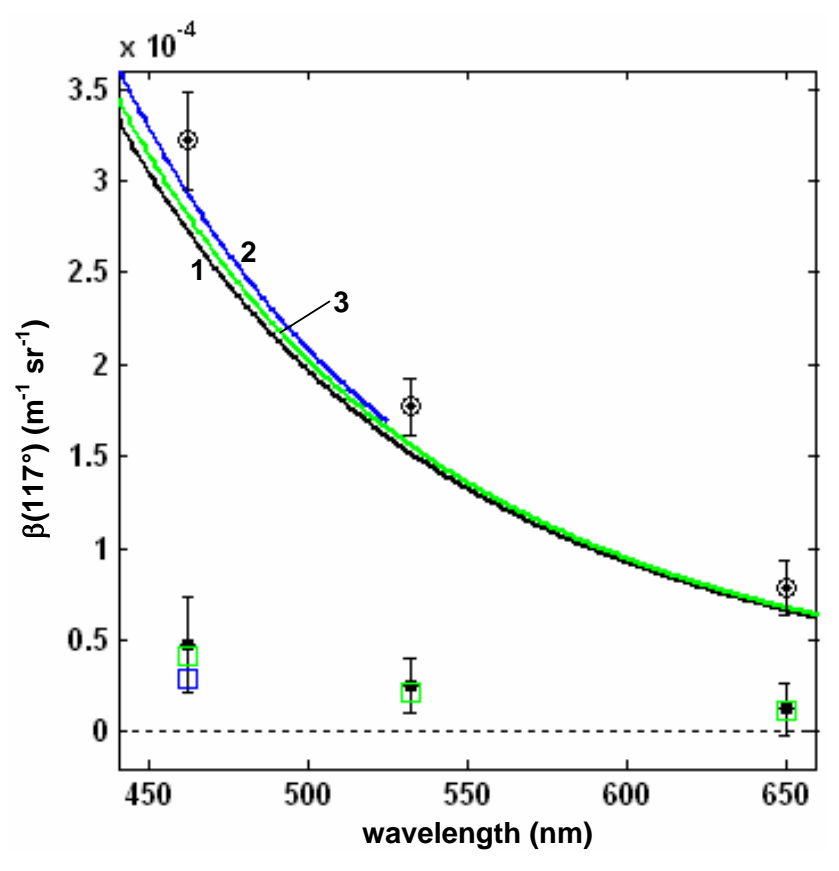

Fig. 4. Means and standard deviations of $\beta_{t}\left(\lambda, 117^{\circ}\right)$ (black circles with central point) and $\beta_{p}\left(\lambda, 117^{\circ}\right)$ (filled black circles) from all 1-m binned measurements collected in the central gyre ( $N=26741$; includes depths from the surface to typically $500 \mathrm{~m}$ ). The parameters $\beta_{p}\left(\lambda, 117^{\circ}\right)$ were computed by subtracting pure seawater volume scattering $\beta_{\text {swB }}\left(\lambda, 117^{\circ}\right)$ according to Eqs. (1) and (2), based on the expressions of Buiteveld et al. (1994) (black curve labeled 1 ; see text for details). The $\beta_{s w M}\left(\lambda, 117^{\circ}\right)$ values computed from Morel (1974) (blue curve labeled 2) and $\beta_{s w S}\left(\lambda, 117^{\circ}\right)$ from Shifrin (1988) (green curve labeled 3) are also plotted, with the spectral range of the former extending only to $525 \mathrm{~nm}$ because a satisfactory model for the Morel values at longer wavelengths is lacking (see Table 2 ). Resulting $\beta_{p}\left(\lambda, 117^{\circ}\right.$ ) means computed using these values are plotted as blue (Morel) and green (Shifrin) squares, respectively; the error bars for these points are the same as shown for the black solid circles, but are left out for clarity. All pure seawater volume scattering coefficients were computed for $\mathrm{T}=20^{\circ} \mathrm{C}$ and $\mathrm{S}=35$.

A final source of error, also scaling with magnitude, is the $\chi_{p}\left(117^{\circ}\right)$ used in computing $b_{b p}$ (Eq. 8). Sullivan et al. (2005) found this uncertainty to be approximately 0.01 , which translates into a $\sim 1 \%$ uncertainty in $b_{b p}$ assuming there were no "sufficiently unusual" particle populations and associated phase functions sampled in this study, i.e., assuming the range in phase function shapes sampled in this study fell within the wide range sampled by Sullivan et al. (2005). Since the $\chi_{p}$ found by Sullivan et al. (2005) was for a different scattering angle, and since their $\chi_{p}$ will also have inherent uncertainties from the $b_{b p}$ derived by multiple angle volume scattering that was used in their regression, uncertainties of a few percent are expected possible.

For details of the methodology for the Hydroscat backscattering sensor data presented here, see Stramski et al. (2007).
Briefly, the Hydroscat measures $\beta_{t}\left(140^{\circ}\right)$ at 6 wavelengths in the visible. To obtain $b_{b p}, \beta_{s w}\left(140^{\circ}\right)$ was subtracted to obtain $\beta_{p}\left(140^{\circ}\right)$, and a $\chi_{p}\left(140^{\circ}\right)$ of 1.13 (Dana and Maffione, 2002) was used to compute $b_{b p}$ from Eq. (8). This sensor was deployed on a profiling package separate from the package containing the ac-9 and ECO-BB3 measurements above. Sampling by both packages typically occurred within a $3 \mathrm{~h}$ period.

Data processing and plotting were performed in MATLAB (Mathworks). Interpolation between casts to map distributions in the central gyre was carried out with Transform (Fortner Software). A spherically weighted fill algorithm was used that preserved all original data, where weights drop off according to the square of the inverse of the distance from a missing data value. This algorithm tends to heavily weight known data close to the missing data elements. A simple smoothing algorithm averaging each data point with each of its directly adjacent neighboring data points was then applied.

\section{Results}

A comparison of ECO-BB3 $b_{b p}(462)$ and Hydroscat $b_{b p}(470)$ data is shown in Fig. 3. These results include data from stations outside the central gyre, extending to the Marquesas Islands and the Chilean upwelling. These were the closest matching wavelengths between the two sensors. Considering that these instruments have different calibration methods, optical configurations (the most obvious being measurement scattering angle), and processing methods, the $\sim 4 \%$ agreement is very good. This result is also consistent with the $\sim 3 \%$ agreement recently observed by Boss et al. (2007) in Crater Lake. The good agreement, particularly for two sensors with independent calibration methods, is a useful factor in helping to constrain accuracy estimates.

Aggregate mean values of $\beta_{t}\left(117^{\circ}\right)$ at 462,532 , and $650 \mathrm{~nm}$ measured with the ECO-BB3 through the entire central gyre (including 0 to $500 \mathrm{~m}$ ) were only $18 \%, 16 \%$, and $20 \%$ higher than the corresponding pure seawater values $\beta_{s w B}\left(\lambda, 117^{\circ}\right)$ (Fig. 4; Table 3). Standard deviations were also small in absolute and relative terms. For example, the standard deviation of $\beta_{t}\left(117^{\circ}\right)$ at $532 \mathrm{~nm}$ was $1.6 \times 10^{-5} \mathrm{~m}^{-1} \mathrm{sr}^{-1}$, or $9 \%$ of the mean magnitude, for the entire data set across the $\sim 3000 \mathrm{~km}$ of the central gyre. After subtracting $\beta_{s w B}\left(\lambda, 117^{\circ}\right)$ to obtain $\beta_{p}\left(\lambda, 117^{\circ}\right)$, mean values were approximately factors of $2.5,5$, and 6 greater than estimated uncertainties for measurements at 462 , $532 \mathrm{~nm}$, and $650 \mathrm{~nm}$, respectively (Table 3 ). Subtracting either $\beta_{s w M}\left(\lambda, 117^{\circ}\right)$ or $\beta_{s w S}\left(\lambda, 117^{\circ}\right)$ resulted in less particulate backscattering, although the means for the entire central gyre data were still positive. 


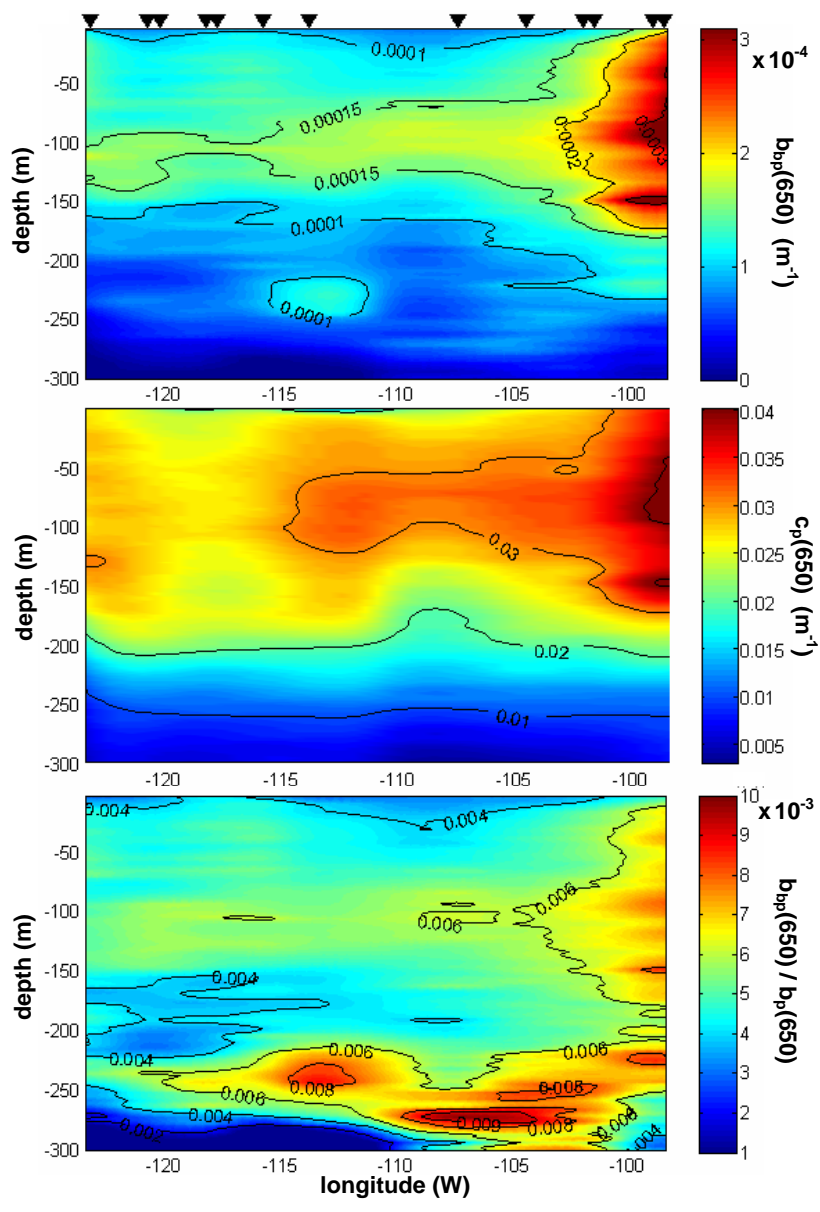

Fig. 5. Distributions of $b_{b p}(650), c_{p}(650)$, and $b_{b p}(650) / b_{p}(650)$ in the South Pacific central gyre. For reference, $b_{b s w B}(650)=4.6 \times 10^{-4} \mathrm{~m}^{-1}$ (see text) and $c_{s w}(650) \approx 0.34 \mathrm{~m}^{-1}$ (assumed equivalent to the pure water absorption values of Pope and Fry 1997, within errors). Cast locations marked along the top of the upper graph. Multiple profiles collected at the same station were averaged.

\subsection{Distributions in the central gyre}

Interpolated distributions of $b_{b p}(650), \quad c_{p}(650)$, and $b_{b p}(650) / b_{p}(650)$ in the central gyre are shown in Fig. 5. A particle peak centered at $\sim 100 \mathrm{~m}$ was observed in both $b_{b p}$ and $c_{p}$. The increase in magnitude heading east is consistent with an increasing proximity to the frontal transition zone between the gyre and the Chilean upwelling region (see Claustre et al., 2007 ${ }^{1}$ ). The parameter $b_{b p} / b_{p}$ was also elevated in this layer (up to $0.6 \%$ and higher east), about $50 \%$ greater than values in surrounding waters. Values of $b_{b p} / b_{p}$ from the surface to $200 \mathrm{~m}$ in the central gyre, ranging from about $0.4 \%$ to $0.6 \%$ west of $104^{\circ} \mathrm{W}$, are indicative of "soft" particles with high water content, such as phytoplankton and possibly loosely assembled detrital aggregates (Twardowski et al., 2001).

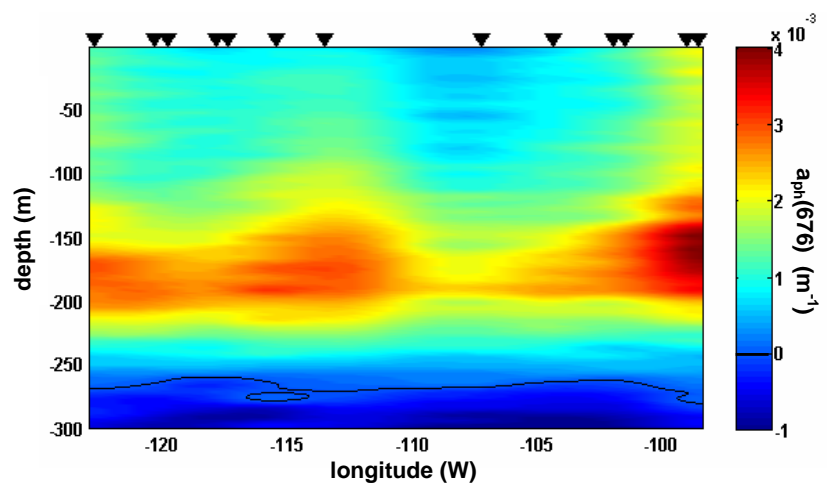

Fig. 6. Distribution of $a_{p h}(676)$ in the central gyre. The contour demarcates zero.

Interestingly, a secondary peak in $b_{b p}(650)$, often observed at depths ranging from $230 \mathrm{~m}$ to $270 \mathrm{~m}$, was not distinct in the $c_{p}$ data. Inspection of $b_{b p} / b_{p}$ revealed relatively high values, approaching $1 \%$, in this deep layer. This could be an indication that the proportion of "hard" particles had increased in this layer (note, however, that both $b_{b p}$ and $c_{p}$ indicate that overall particle concentrations are very low relative to the overlying water). It may also be possible that substantial increases in the relative amount of small particles (a few microns and less) could also increase the backscattering ratio in this layer (Twardowski et al., 2001), but the $c_{p}$ spectral slope, related to mean particle size (Boss et al., 2001), did not support this hypothesis (data not shown). However, $b_{b p}$ and $c_{p}$ are affected by different portions of the size distribution (Stramski and Kiefer, 1991), with $b_{b p}$ being much more sensitive to small (submicron) particles, thus it is not inconceivable that the two could become decoupled.

Distributions of $a_{p h}(676)$ revealed a deep chlorophyll maximum spanning 160 to $210 \mathrm{~m}$ depth (Fig. 6) that was also consistent with ancillary chlorophyll fluorescence measurements (Claustre et al., 2007 ${ }^{1}$ ) and HPLC pigment data (Ras et al., 2007). This deep chlorophyll layer corresponded to a minimum in $b_{b p} / b_{p}$ of $\sim 0.4 \%$ (see Fig. 5). Bulk particle refractive indices in this layer estimated from the model of Twardowski et al. (2001) are 1.03, in agreement with previous estimates of refractive indices of phytoplankton (Carder et al., 1972; Aas 1996; Stramski et al., 2001).

An overlay of all the profiles of computed $b_{b p}$ collected at the central gyre stations shows a structure that is typically very consistent for each wavelength (Fig. 7). This consistency lends support to our assumption that the drift in ECOBB3 calibration parameters was negligible during this period of the cruise. Spectrally, particulate backscattering showed a typical decrease with increasing wavelength. The primary particle maximum centered $\sim 100 \mathrm{~m}$ is identified in backscattering at all three wavelengths. The secondary maximum centered at $\sim 230 \mathrm{~m}$ is distinct in $b_{b p}$ at 532 and $650 \mathrm{~nm}$, but is only weakly present at $462 \mathrm{~nm}$. Furthermore, a clear 


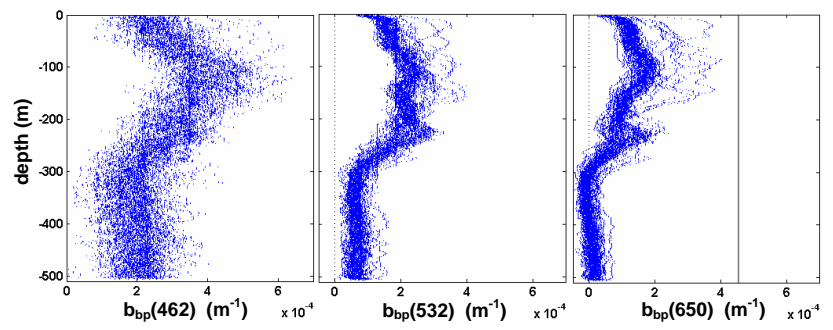

Fig. 7. All profiles $(\mathrm{N}=56)$ of $b_{b p}$ at 462,532 , and $650 \mathrm{~nm}$ from the central gyre, plotted at 1-m depth bins using a 10-point median filter. The lowest values were typically observed at 300-350 m depth. Backscattering by pure seawater falls within the plotted $b_{b p}$ range for $650 \mathrm{~nm}$, and is drawn in as a gray line. Faint vertical banding can be seen, particularly in the $b_{b p}(532)$ data, due to occasions where the raw digital counts included in a depth bin were all the same value.

minimum in $b_{b p}(650)$ is present between 160 and $210 \mathrm{~m}-$ the depth of the chlorophyll maximum, see Fig. 6 - that is also apparent in $b_{b p}(532)$, but not obvious in the noisier data at $462 \mathrm{~nm}$.

This spectral variability becomes apparent when viewing spectral ratios (Fig. 8). Both sets of spectral ratio profiles were essentially constant in the surface $\sim 140 \mathrm{~m}$, despite substantial changes in $b_{b p}$ magnitude (Fig. 7). This is a reassuring observation, as bias errors in uncertainties can manifest themselves in ratios that are magnitude dependent. Below $140 \mathrm{~m}$, both ratios increased to a peak in the depth range of the chlorophyll maximum, then decreased to a minimum centered at $\sim 230 \mathrm{~m}$. Below $230 \mathrm{~m}$, the ratios began increasing in deeper water where uncertainties rapidly made the ratios unresolvable.

The widely assumed $1 / \lambda$ spectral model predicts ratios of 1.41 and 1.22 for $b_{b p}(462) / b_{b p}(650)$ and $b_{b p}(532) / b_{b p}(650)$, respectively. The latter ratio was in fact observed from the surface down to $\sim 140 \mathrm{~m}$. The spectral shape of particulate attenuation in the clearest waters west of $115^{\circ} \mathrm{W}$ was also approximately $1 / \lambda$ (data not shown). This is the predicted case for particles with minimal absorption that follow a Jungetype hyperbolic size distribution with slope of 4 (volume conserved in all size bins) (Morel 1973; Fournier and Forand 1994; Boss et al., 2001). This distribution was moreover verified in Coulter Counter data from the cruise (see Sciandra et al., $2007^{3}$ ). This slope is often considered to be representative of oceanic particle distributions, and is the predicted "steady state" condition from physical (see Sullivan et al., 2005) and biological (Kiefer and Berwald, 1992) mechanistic processes. For $b_{b p}(462) / b_{b p}(650)$, ratios at the surface to $\sim 140 \mathrm{~m}$ were about $50 \%$ greater than the value expected from the $1 / \lambda$ model. The fact that the $1 / \lambda$ model did not hold

\footnotetext{
${ }^{3}$ Sciandra, A., Stramski, D. and Babin, M.: Variablity in particle size distribution in contrasted trophic regions of the South East Pacific, Biogeosci. Discuss., in preparation, 2007.
}

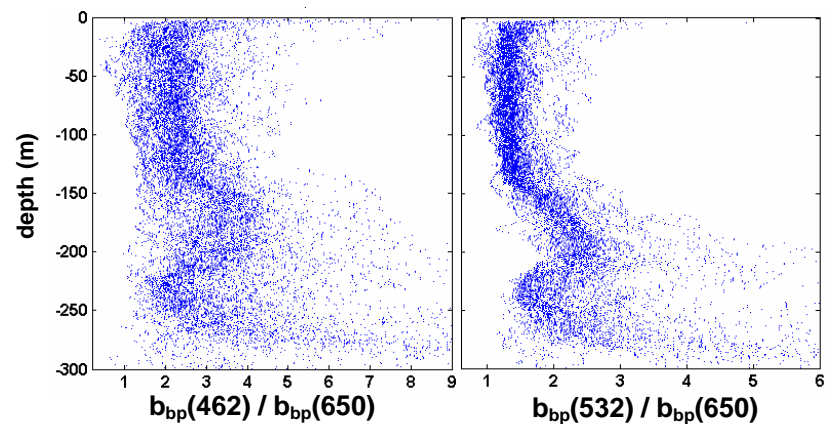

Fig. 8. Profiles $(\mathrm{N}=49)$ of $b_{b p}(462) / b_{b p}(650)$ and $b_{b p}(532) / b_{b p}(650)$ from the central gyre. Only profiles collected west of $104^{\circ} \mathrm{W}$, inclusive, are shown to avoid including the slightly more turbid waters with closer proximity to the frontal zone transition to the Chilean upwelling. A $1 / \lambda$ spectral model predicts a ratio of 1.41 for $b_{b p}(462) / b_{b p}(650)$ and 1.22 for $b_{b p}(532) / b_{b p}(650)$.

into the blue is difficult to interpret at this time because our understanding of spectral particulate backscattering in natural waters is unfortunately very limited. Factors such as nonsphericity and anomalous dispersion from particulate absorption structure altering complex index of refraction spectra may play important, but poorly understood, roles. The agreement with independent Hydroscat data (Fig. 3) is a good indication that there are probably no substantial bias errors in the data.

Below $140 \mathrm{~m}$, the ratio $b_{b p}(532) / b_{b p}(650)$ increased to a value of $\sim 2.2$ in the deep chlorophyll maximum (160 to $210 \mathrm{~m}$ depth range), corresponding to a $\sim \lambda^{-4}$ spectral shape. Furthermore, $b_{b p}(462) / b_{b p}(650)$ increased to values up to 3.9 at these depths, also consistent with a $\sim \lambda^{-4}$ spectral shape. This is the spectral shape of Rayleigh scattering, an indication that the particle population in this layer may be dominated by particles much smaller than the wavelengths of light scattered. The $c_{p}(\lambda)$ spectral slope increased in the chlorophyll maximum as well, but only to a value of $\sim 1.5$ (data not shown).

Microscope taxonomy (Gomez et al., 2007) and HPLC pigment analyses (Ras et al., 2007) on discrete samples have determined that the phytoplankton assemblage in the deep chlorophyll maximum consisted primarily of cyanobacteria, which have cell diameters of the same order as the wavelengths of light used in the scattering measurements here. Moreover, these cells would not be expected to be Rayleigh scatterers; this is verified in modeled (Morel et al., 1993) and measured (Vallaincourt et al., 2004) backscattering spectra of cyanobacteria. Factors such as nonsphericity and anomalous dispersion that may affect backscattering spectra in ways not predicted by simple Mie theory, are unlikely to have caused the $\sim \lambda^{-4}$ shape because (1) the cells are small (Clavano et al., 2007) and (2) the spectral distribution of pigment absorption, while introducing oscillations in the backscattering 


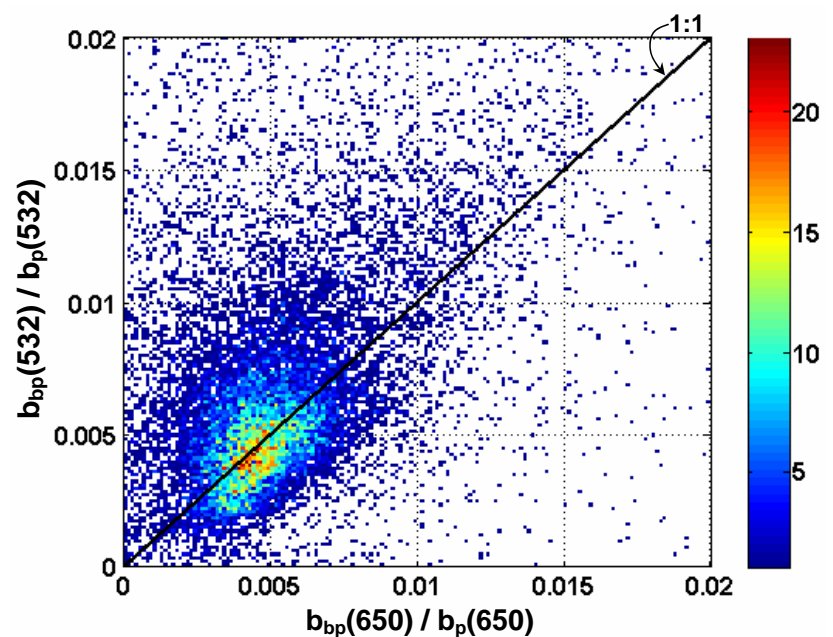

Fig. 9. Relationship between $b_{b p}(532) / b_{p}(532)$ and $b_{b p}(650) / b_{p}(650)$ for all $1-\mathrm{m}$ binned measurements from the central gyre. Color denotes frequency.

spectrum over small wavelength ranges, typically tends to impose a broad flattening of the spectrum when the full visible range is considered (Stramski et al., 2001). Thus, to explain the steep spectral slope in backscattering, one would likely need to invoke a large relative population of colloidal particles $(<0.2 \mu \mathrm{m})$ that may include viruses.

The lowest values of $b_{b p}$ were observed at 300 to $350 \mathrm{~m}$ depth (Fig. 7; Table 3). For $b_{b p}(650)$, the lowest mean values recorded were negative with a magnitude about our estimated uncertainty for the measurement. These scattering levels are also certainly pushing the limits of our uncertainty in pure seawater values. Overall, however, uncertainties appeared sufficiently good to resolve particulate backscattering in these extremely clear waters.

Previous theoretical analyses have predicted $b_{b p} / b_{p}$ should exhibit minimal spectral dependence (Ulloa et al., 1994; Twardowski et al., 2001) and this has been supported through a growing body of field work (Boss et al., 2004; Chami et al., 2005; Oubelkier et al., 2006). For the central gyre, the relationship between $b_{b p}(532) / b_{p}(532)$ and $b_{b p}(650) / b_{p}(650)$ showed substantial scatter because of propagation of random errors, but a clear peak in the distribution was observed on the 1:1 relationship (Fig. 9), supporting previous findings.

Despite this broad concentration of data around the $1: 1$ relationship, it is also noteworthy that consistent deviations from this relationship were observed in the deep chlorophyll maximum (data not independently shown). The 1:1 relationship increased up to $1.5: 1$ $\left[b_{b p}(532) / b_{p}(532): b_{b p}(650) / b_{p}(650)\right]$ within the maximum. This is consistent with the previous observation that the $b_{b p}$ slope increases in this layer were greater in magnitude than $c_{p}$ slope increases.
Table 3. Parameters from scattering measurements in the South Pacific central gyre. All values expressed in $10^{-4}$.

\begin{tabular}{|c|c|c|c|}
\hline \multirow[b]{2}{*}{ parameter } & \multicolumn{3}{|c|}{$\lambda(\mathrm{nm})$} \\
\hline & 462 & 532 & 650 \\
\hline $\begin{array}{l}\beta_{t}\left(117^{\circ}\right)\left(\mathrm{m}^{-1} \mathrm{sr}^{-1}\right) \\
\text { raw uncertainty }\end{array}$ & 0.17 & 0.044 & 0.016 \\
\hline $\begin{array}{l}\beta_{t}\left(117^{\circ}\right)\left(\mathrm{m}^{-1} \mathrm{sr}^{-1}\right) \\
\text { estimated uncertainty }\end{array}$ & 0.2 & 0.05 & 0.02 \\
\hline$\beta_{s w B}{ }^{\mathrm{c}}\left(117^{\circ}\right)\left(\mathrm{m}^{-1} \mathrm{sr}^{-1}\right)$ & 2.72 & 1.52 & 0.66 \\
\hline$b_{b s w B}{ }^{\mathrm{c}}\left(\mathrm{m}^{-1}\right)$ & 18.7 & 10.5 & 4.6 \\
\hline $\begin{array}{l}\beta_{t}\left(117^{\circ}\right) \text {, mean } \pm \sigma\left(\mathrm{m}^{-1} \mathrm{sr}^{-1}\right) \\
\text { central gyre, } 0-500 \mathrm{~m}\end{array}$ & $3.2 \pm 0.3$ & $1.77 \pm 0.16$ & $0.79 \pm 0.15$ \\
\hline $\begin{array}{l}b_{b p}\left(\mathrm{~m}^{-1}\right) \\
\text { estimated uncertainty }\end{array}$ & 1.4 & 0.51 & 0.22 \\
\hline $\begin{array}{l}b_{b p}, \text { mean } \pm \sigma\left(\mathrm{m}^{-1}\right) \\
\text { central gyre, } 0-500 \mathrm{~m}\end{array}$ & $2.7 \pm 1.5$ & $1.42 \pm 0.87$ & $0.71 \pm 0.81$ \\
\hline $\begin{array}{l}b_{b p}, \text { mean } \pm \sigma\left(\mathrm{m}^{-1}\right) \\
\text { central gyre, } 300-500 \mathrm{~m}\end{array}$ & $2.0 \pm 1.2$ & $0.68 \pm 0.39$ & $0.04 \pm 0.37$ \\
\hline$b_{b p}$, lowest measured $\left(\mathrm{m}^{-1}\right)$ & 0.92 & 0.37 & $\sim 0$ \\
\hline
\end{tabular}

a i.e., random electronic error

${ }^{\mathrm{b}}$ Computed over 1-m depth bins; see text.

c Pure water scattering computed from Buiteveld et al. (1994) at $20^{\circ} \mathrm{C}$; [1+0.3(35)/37] adjustment for dissolved salts applied after Morel (1974).

$\mathrm{d}$ Assumes the mean central gyre value, a 5\% uncertainty in $\beta_{s w B}\left(117^{\circ}\right)$, and a $5 \%$ uncertainty in $\chi_{p}\left(117^{\circ}\right)$ (note both uncertainties would be bias errors).

\subsection{Time series at the central gyre station, GYR}

To resolve diel scale temporal variability in the central gyre, casts were collected every few hours over a $4 \mathrm{~d}$ period at station GYR (Fig. 10). The parameter $c_{p}(650)$ shows a clear diel cycle in the broad particle maximum centered around $90 \mathrm{~m}$ depth, reaching maxima around sunset and minima around sunrise. This pattern is consistent with previous observations from the South Pacific (Claustre et al., 1999) and other oceanic locations (e.g. Siegel et al., 1989; Gardner et al., 1995; Walsh et al., 1995), and results from the interaction of several processes, including accumulation of particles through algal growth, synchronized cell division, the removal of particles via loss terms such as grazing, and cellular physiological changes that may affect particle optical properties. This pattern was much less pronounced in the corresponding $b_{b p}(650)$ data, an indication that submicron particles more strongly affecting $b_{b p}(650)$ may not show the same marked cycling observed in $c_{p}(650)$. The $b_{b p} / b_{p}$ parameter exhibits a small increase in the $\sim 90 \mathrm{~m}$ particle maximum, as observed throughout the gyre in Fig. 5.

The secondary peak in $b_{b p}$ at 230-250 $\mathrm{m}$ depth was especially pronounced throughout the time series at this station (Fig. 10). Again, the layer was not distinct in the $c_{p}$ time series data and the $b_{b p} / b_{p}$ exhibited a strong increase, reaching 


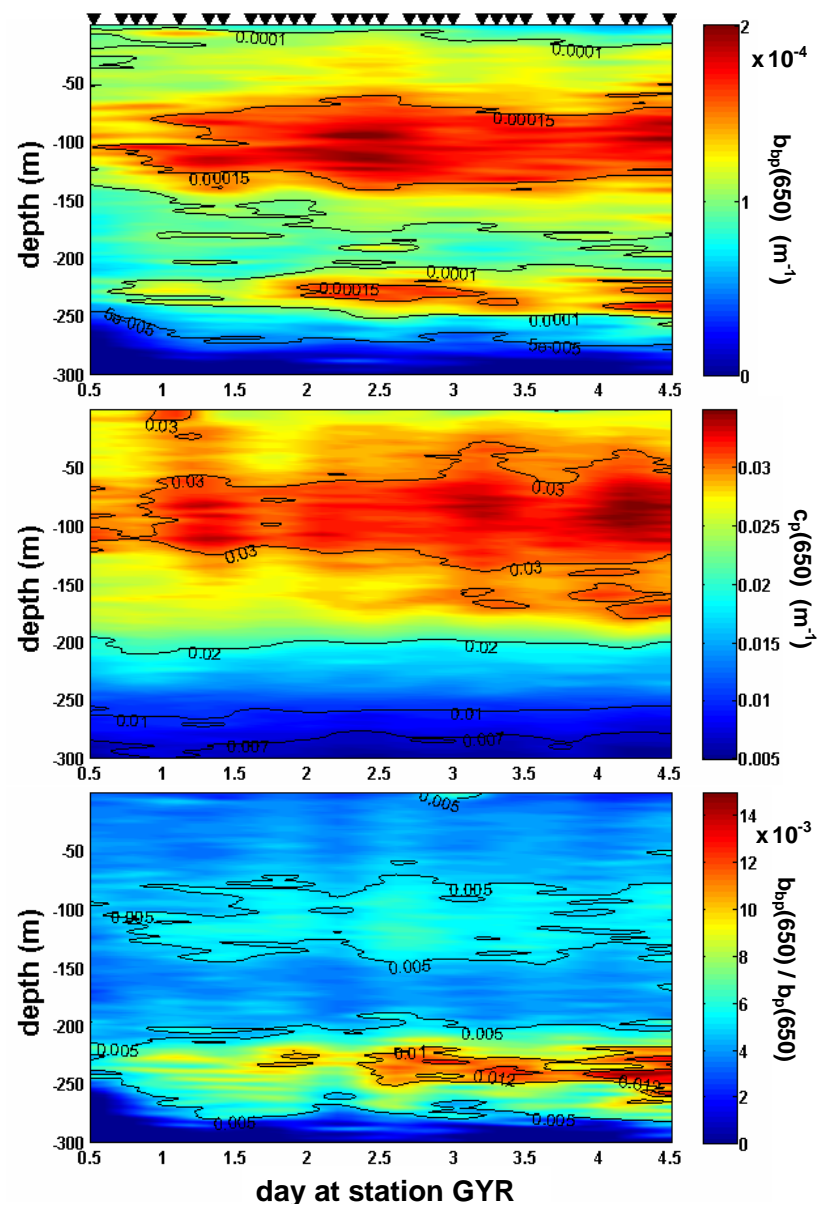

Fig. 10. Time series measurements of $b_{b p}(650), c_{p}(650)$, and $b_{b p}(650) / b_{p}(650)$ at station GYR. Day 0 corresponds to 00:00 UTC, 12 November 2004 (subtract $7 \mathrm{~h}$ to convert to local time). Cast times marked along the top of the upper graph.

a maximum of greater than $1.2 \%$ at some times (note that all of the time series profile data from this station was averaged to obtain the data for the $114^{\circ} \mathrm{W}$ profile used in the distribution plot in Fig. 6). There may be a very faint diel pattern to the intensity of the deep $b_{b p} / b_{p}$ layer, but an analysis with the density structure indicates that the layer location and magnitude appear to be primarily modulated by the internal wave field through the sampling period.

\subsection{Reflectance estimation, testing closure}

At station GYR, surface reflectance $\mathrm{R}$ measurements at $532 \mathrm{~nm}$ reported in Morel et al. (2007) were $1.15 \%$ and $1.08 \%$ at depths of 1.49 and $2.1 \mathrm{~m}$, respectively. These measurements were made at approximately noon on 15 November 2004 (labelled station "GYR-5" in Morel et al., 2007) concurrently with IOP measurements (in Fig. 10, cast made at day 3.79). Using the radiative transfer approximation in Eq. (4) of Morel et al. (2007), $R=f^{\prime}\left[b_{b} /\left(a+b_{b}\right)\right], R$ can be solved from the IOPs and a suitable $f^{\prime}$ parameter. Using the $f^{\prime}$ provided in lookup tables referenced in Morel et al. (2007) and derived previously by Morel and Gentili (2004), surface $R$ was independently estimated at $1.11 \%$ with directly measured $b_{b t}(532)$ and $a_{t}(532)$ (the $f^{\prime}$ value used was 0.456 and surface $a_{t}$ and $b_{b t}$ values were $0.047 \mathrm{~m}^{-1}$ and $1.18 \times 10^{-3} \mathrm{~m}^{-1}$, respectively). Demonstrating closure with the measurements of Morel et al. (2007) helps to validate the accuracy of our measurements. These results also demonstrate the practical potential of using IOPs to derive remote sensing parameters with good precision.

\section{Discussion}

Estimated uncertainties in direct measurements of $b_{b}$ were approximately two orders of magnitude better than uncertainties in results from inverting reflectance measurements (Morel et al., 2007). Better precision in direct measurements of a parameter as opposed to derivation from an inversion may be reasonably expected. Considered together, the two sets of measurements form an excellent complement in characterizing optical properties in the clearest natural waters.

Several aspects of this work were enlightening, and, we believe, significant. Foremost, scattering at $117^{\circ}$ was resolved at very low levels. For example, estimated uncertainties were approximately $6 \%, 3 \%$, and $3 \%$ of pure scattering of seawater at 462,532 , and $650 \mathrm{~nm}$, respectively (Table 3 ). In these clear waters, particulate backscattering could be resolved at better than a few factors of uncertainty except in the very clearest waters deeper than $\sim 300 \mathrm{~m}$. Additional depthbin averaging in the deep water (or collecting time series at depth to average) could help improve uncertainties (but not any bias errors). We believe a key improvement in methodology relative to previous measurements that helped improve uncertainties was the direct in-situ determination of dark offsets (see Sect. 3.2).

Good agreement was observed between the ECO-BB3 and Hydroscat sensors. The most important difference between these sensors is the calibration method. Calibration of scattering devices requires a "known" scattering medium - this is a Lambertian (isotropic scattering) Spectralon plaque for the Hydroscat (Maffione and Dana, 1997), whereas microspherical bead suspensions are used for the ECO-BB3 (also see Volten et al., 1997; Lee and Lewis, 2003; Slade and Boss, 2005). The $\sim 4 \%$ agreement observed is an indication that our estimated accuracies for the ECO-BB3 may be as low as a few percent.

It is interesting to note that a closer look at previous comparisons between ECO scattering sensors and the Hydroscat (e.g., Pegau et al., 2001; Prentice et al., 2002; Boss et al., 2004) reveals that the reported " $10 \%$ agreement" was not only consistent, but that the Hydroscat was consistently about 10\% lower than the ECO-BB3 (E. Boss, University of Maine, personal communication, 2007). Furthermore, a new 
correction has been implemented recently for the Hydroscat that accounts for a change in reflectivity of the Spectralon plaque used for calibrations when it is immersed in water versus air (E. Boss, University of Maine, personal communication, 2007). This correction enhances values by about $10 \%$. This may explain both the previous consistent discrepancies as well as the good agreements that are now being observed.

A further result of this work we found significant was the apparent accuracy of both the Buiteveld et al. (1994) pure water scattering values and the $[1+0.3 \mathrm{~S} / 37]$ empirical adjustment for salts based on Morel (1974). Useful diagnostics in this analysis are the observed particulate backscattering ratios and spectral ratios (Figs. 5, 8-10). For $b_{b p}$ alone, it is difficult to surmise what a reasonable expectation for absolute magnitude should be in the South Pacific gyre, but previous theoretical and experimental work has determined and verified expected ranges for these ratios (Twardowski et al., 2001; Boss et al., 2004; Sullivan et al., 2005; Twardowski et al., 2006; Loisel et al., 2007). Measured $b_{b p} / b_{p}$ from the central gyre fall within the range expected, indicative of the "soft," water-filled organic particles one would expect in the open ocean (Twardowski et al., 2001). In fact, from an analysis of field data (not including the current data) and measurements in culture, Twardowski et al. (2006) concluded that the $b_{b p} / b_{p}$ of phytoplankton dominated particle assemblages "generally tends to converge on a value around $0.5 \%$," which closely agrees with the measurements here. Note that the $b_{p}$ used in this ratio and in the Twardowski et al. (2006) analysis includes volume scattering from $\sim 0.93^{\circ}$ to $\sim 180^{\circ}$ based on the acceptance angle of the ac- 9 attenuation measurement.

In the surface layer extending to $140 \mathrm{~m}$, the spectral ratio $b_{b p}(532) / b_{b p}(650)$ matched expectations from the $1 / \lambda$ model for oceanic backscattering, assuming a Junge-type size distribution of particles (slope $\sim 4$ ) with minimal absorption (e.g., Morel 1973, 1988). Furthermore, the relationship between $b_{b p}(532) / b_{p}(532)$ and $b_{b p}(650) / b_{p}(650)$ clustered around a 1:1 agreement, also matching expectations. In total, these observations are good evidence that the magnitudes of $b_{b p}(532)$ and $b_{b p}(650)$, which can be considered fully independent measurements, appear accurate at the level of our estimated uncertainties.

These uncertainties for the $b_{b p}(532)$ and $b_{b p}(650)$ values are not only dependent on the uncertainties in the measurement, but also on the uncertainties in the estimates of pure seawater scattering used. These results suggest $b_{s w B}$ values are accurate at the $1 \times 10^{-5} \mathrm{~m}^{-1}$ level in the red. Note that Buiteveld et al. (1994) only reported results from their calculations at $20^{\circ} \mathrm{C}$ to the fourth decimal place. Buiteveld et al. (1994) estimate their accuracy at $6 \%$, which, for $b_{b w}(650)=3.5 \times 10^{-4} \mathrm{~m}^{-1}$, corresponds to a $2 \times 10^{-5} \mathrm{~m}^{-1}$ uncertainty, consistent with findings here. It was also necessary in these extremely clear waters that the ambient water temperature be used in the computation of $b_{b w}$ to achieve the most accurate results. These results support the use of $\delta=0.051$ after Farinato and Roswell (1976). However, since Farinato and Roswell is a single study that lowered a previously accepted constant (Morel, 1974; Shifrin, 1988) by more than $40 \%$, this is certainly a topic that could benefit from additional investigation. In fact, Jonasz and Fournier (2007) have recently recommended the use of $\delta=0.039$ based on another interpretation of the data of Farinato and Roswell (1976), highlighting the substantial uncertainty that remains in this constant.

Additionally, the $\sim 30 \%$ increase relative to pure water scattering recommended by Morel (1974), would also appear accurate at a high level. If we make the cautious assumption based on the $b_{b p} / b_{p}$ and spectral results that the $b_{b p}(650)$ values were accurate within $20 \%$, this would translate to a $30 \pm 3 \%$ range for the effects of salts at a salinity of 37 , assuming the values from Buiteveld et al. (1994) were exact. After a close examination, this very good accuracy may actually be quite consistent with the original measurements of Morel (1966). Firstly, Morel's measurements of $\beta\left(90^{\circ}\right)$ with purified water and with a sample of purified Mediterranean seawater were made relative to benzene, so that the absolute values relied on accurate absolute scattering values for benzene. However, the enhancement in molecular scattering due to seawater was obtained as a ratio of the relative Mediterranean seawater values and the relative pure water values, so that any bias errors associated with calibration cancel. Furthermore, pure water and pure seawater $\beta\left(90^{\circ}\right)$ were resolved at five wavelengths, from 366 to $578 \mathrm{~nm}$, allowing some statistics; the resulting standard deviation around the 1.30 enhancement was 0.01 . Morel (1966) could additionally demonstrate through theory that other measurements in artificial seawater and $\mathrm{NaCl}$ solutions generally supported the $30 \%$ enhancement. As a result, we can conclude that aggregate uncertainties of the best pure seawater estimates, i.e., the values of Buiteveld et al. (1994) with Morel's salinity enhancement, would appear to be on the order of just a few percent.

The presence of a unique particle layer centered at $\sim 230 \mathrm{~m}$ was only apparent in backscattering measurements. One explanation for this increased backscattering may be the presence of a layer of coccolithophorids and associated free coccoliths at depth (Honjo and Okada, 1974). An obvious candidate coccolithophorid for this deep layer is Florisphaera profunda, known to occupy a niche in the lower photic zone $(<1 \%$ surface irradiance) at the top of the nutricline in subtropical and tropical regions throughout the world's oceans (Molfino and McIntyre, 1990; Jordan and Chamberlain, 1997; Malinverno et al., 2003). This species was identified in the deepest samples analyzed from the GYR station (depth of $190 \mathrm{~m}$; Luc Beaufort, personal communication, 2007). HPLC pigment analyses additionally identified the coccolithophorid (Prymnesiophyte) pigment 19'hexanoxyfucoxanthin in samples in the deep layer (Ras et al., 2007). Another clue with respect to the ecological niche was that the depth of the backscattering peak, $\sim 230 \mathrm{~m}$, 
corresponded to the precise location of the upper boundary of the nutricline (M. Lewis, Dalhousie University, personal communication, 2007). These observations support the presence of a deep coccolithophorid layer with a uniquely identifiable backscattering signature. It is an interesting note that this particular coccolithophorid species, with unique subrectangular plates, is the dominant coccolithophorid in sediment fossil assemblages when nutriclines are found extending only into the lower photic zone, as is the case in the South Pacific gyre (Molfino and McIntyre, 1990; Jordan and Chamberlain, 1997). Thus, the ecology associated with this deep backscattering layer may not simply be a peculiar oddity, but may play a key role in the transfer of carbon to the sediments in these regions.

Another explanation investigated for the deep backscattering peak was possible contamination of the backscattering signals at 532 and $650 \mathrm{~nm}$ from Prochlorococcus pigments fluorescence. The interference filters used in front of the detectors of the ECO-BB3 have a full-width-half-maximum of 30 and $20 \mathrm{~nm}$ at 532 and $650 \mathrm{~nm}$, respectively. It may be possible, if the filter is appropriately located, that fluorescence effects of some pigments with a small Stokes shift may be detectable, particularly in these ultra clear waters. This was deemed unlikely, however, after looking at the pigment distributions obtained from HPLC analyses (Ras et al., 2007). Prochlorococcus pigments such as divinyl chl-a (chl$a_{2}$ ) and divinyl chl-b (chl- $b_{2}$ ) peak in the lower depths of the deep chlorophyll maximum, typically around $200 \mathrm{~m}$ at the GYR station, or $30 \mathrm{~m}$ shallower in the water column than the apparent peak in backscattering. This trend was consistent throughout the central gyre.

At 462 and $532 \mathrm{~nm}$, the lowest $b_{b p}$ values in the central gyre, $9.2 \times 10^{-5}$ and $3.7 \times 10^{-5} \mathrm{~m}^{-1}$, respectively, were found between $115^{\circ}$ and $118^{\circ} \mathrm{W}$ longitude in the depth range of 300 to $350 \mathrm{~m}$. At these locations and depths, $b_{b p}(650)$ reached minimums not distinguishable from the pure seawater backscattering values of Buiteveld et al. (1994) multiplied by [1+0.3S/37] from Morel 1974 to account for salts. To our knowledge, these values are about an order of magnitude lower than the lowest previous particulate backscattering measurements made by Boss et al. (2007) in Crater Lake and Stramska and Stramski (2005) in the Greenland Sea.

The ability to resolve total and particulate backscattering structure in the very clear South Pacific central gyre demonstrates the possibility that these optical properties can be effective proxies for biogeochemical parameters in almost any natural waters. Future work will more closely evaluate the relationships between the particle scattering properties and the biogeochemical determinations of particle concentrations and composition.

Acknowledgements. M. Twardowski gratefully acknowledges support for this work from the U.S. Office of Naval Research Optics and Biology and SBIR Programs and the NASA Biology and Biogeochemistry and SBIR Programs. D. Merien was of valuable assistance in the field and we thank him for his efforts. D. Tailliez and C. Bournot are warmly thanked for their efficient help in CTD rosette management and data processing. Many helpful discussions with R. Zaneveld, C. Moore, J. Sullivan, E. Boss, and A. Morel improved this work. In particular, comments by E. Boss on an earlier version of the manuscript helped to evolve interpretations and improve clarity in a number of sections. This is a contribution of the BIOSOPE project of the LEFE-CYBER program. This project was funded by the Centre National de la Recherche Scientifique (CNRS), the Institut des Sciences de l'Univers (INSU), the Centre National d'Etudes Spatiales (CNES), the European Space Agency (ESA), The National Aeronautics and Space Administration (NASA) and the Natural Sciences and Engineering Research Council of Canada (NSERC).

Edited by: E. Boss

\section{References}

Aas, E.: Refractive index of phytoplankton derived from its metabolite composition, J. Plankton Res., 18(12), 2223-2249, 1996.

Balch, W. M., Drapeau, D. T., Cucci, T. L., Vaillancourt, R. D., Kilpatrick, K. A., and Fritz, J. J.: Optical backscattering by calcifying algae: separating the contribution by particulate inorganic and organic carbon fractions, J. Geophys. Res., 104, 1541-1558, 1999.

Balch, W. M., Gordon, H., Bowler, B. C., Drapeau, D. T., and Booth, E. S.: Calcium carbonate measurements in the surface global ocean based on Moderate-Resolution Imaging Spectroradiometer data, J. Geophys. Res., 110, C07001, doi:10.1029/2004JC002560, 2005.

Bohren, C. J. and Huffman, D. R.: Absorption and scattering of light by small particles, Wiley, New York, 530 pp., 1983.

Boss, E. and Pegau, W. S.: Relationship of light scattered at an angle in the backward direction to the backscattering coefficient, Appl. Opt., 40, 5503-5507, 2001.

Boss, E., Twardowski, M. S., and Herring, S.: Shape of the particulate beam attenuation spectrum and its inversion to obtain the shape of the particulate size distribution, Appl. Opt., 40, 48854893, 2001.

Boss, E., Pegau, W. S., Lee, M., Twardowski, M. S., Shybanov, W., Korotaev, G., and Baratange, F.: The particulate backscattering ratio at LEO 15 and its use to study particles composition and distribution, J. Geophys. Res., 109, C01014, doi:10.1029/2002JC001514, 2004.

Boss, E., Collier, R., Larson, G., Fennel, K., and Pegau, W. S.: Measurements of spectral optical properties and their relation to biogeochemical variables and processes in Crater Lake, Crater Lake National Park, OR, Hydrobiologia, 574, 149-159, 2007.

Bricaud, A. and Stramski, D.: Spectral absorption coefficients of living phytoplankton and nonalgal biogenous matter: A comparison between Peru upwelling area and the Sargasso Sea, Limnol. Oceanogr., 35, 562-582, 1990.

Buiteveld, H., Hakvoort, J. H. M., and Donze, M.: The optical properties of pure water, SPIE Ocean Optics XII, 2258, 174-183, 1994.

Carder, K. L., Tomlinson, R. D., and Beardsley Jr., G. F.: A technique for the estimation of indices of refraction of marine phytoplankters, Limnol. Oceanogr., 17, 833-839, 1972. 
Chami, M., Shybanov, E. B., Churilova, T. Y., Khomenko, G. A., Lee, M. E.-G., Martynov, O. V., Berseneva, G. A., and Korotaev, G. K.: Optical properties of the particles in the Crimea coastal waters (Black Sea), J. Geophys. Res., 110, C11020, doi:10.1029/2005JC003008, 2005.

Clavano, W. R., Boss, E., and Karp-Boss, L.: Inherent optical properties of non-spherical marine-like particles - from theory to observation. Oceanography and Marine Biology, An Annual Review, 45, 1-38, 2007.

Claustre, H., Morel, A., Babin, M., Cailliau, C., Marie, D., Marty, J-C., Tailliez, D., and Vaulot, D.: Variability in particle attenuation and chlorophyll fluorescence in the tropical Pacific: scales, patterns, and biogeochemical implications, J. Geophys. Res., 104(C2), 3401-3422, 1999.

Dana, D. R. and Maffione, R. A.: Determining the backward scattering coefficient with fixed-angle backscattering sensors - Revisited, Ocean Optics XVI, Santa Fe, New Mexico, November, 18-22, 2002.

Davis, R. F., Moore, C. C., Zaneveld, J. R. V., and Napp, J. M.: Reducing the effects of fouling on chlorophyll estimates derived from long-term deployments of optical instruments, J. Geophys. Res., 102, 5821-5855, 1997.

Evtyushenko, A. M. and Kiyachenko, Y. F.: Determination of the dependence of liquid refractive index on pressure and temperature, Opt. Spectrosc., 52, 56-58, 1982.

Farinato, R. S. and Roswell, R. L.: New values of the light scattering depolarization and anisotropy of water, J. Chem. Phys., 65, 593-595, 1976

Fournier, G. R. and Forand, J. L.: Analytical phase function for ocean water, Ocean Optics XII, edited by: Jaffe J. S., Proc. SPIE, 2258, 194-201, 1994.

Gardner, W. D., Chung, S. P., Richardson, M. J., and Walsh, I. D.: The oceanic mixed-layer pump, Deep Sea Res. Part II , 42, 757 $775,1995$.

Gordon, H. R.: Backscattering of light from disk-like particles: is fine-scale structure or gross morphology more important?, Appl. Opt., 45, 7166-7173, 2006.

Gordon, H. R.: Rayleigh-Gans scattering approximation: surprisingly useful for understanding backscattering from disk-like particles, Opt. Express, 15(9), 5572-5588, 2007.

Honjo, S. and Okada, H.: Community structure of coccolithophores in the photic layer of the mid-Pacific, Micropaleontology, 20(2), 209-230, 1974.

Jonasz, M. and Fournier, G.: Light scattering by particles in water, Academic Press, Amsterdam, Netherlands, 704 pp., 2007.

Jordan, R. W. and Chamberlain, A. H. L.: Biodiversity among haptophyte algae, Biodivers. Conserv., 6, 131-152, 1997.

Kiefer D. A. and Berwald, J.: A random encounter model for the microbial planktonic community, Limnol. Oceanogr., 37(3), 457467, 1992

Lee, M. E. and Lewis, M. R.: A new method for the measurement of the optical volume scattering function in the upper ocean, J. Atmos. Oceanic Technol., 20(4), 563-571, 2003.

Lepple, F. K. and Millero, F. J.: The isothermal compressibility of seawater near one atmosphere, Deep-Sea Res., 18, 1233-1254, 1971.

Loisel, H., Meriaux, X., Berthon, J.-F., and Poteau, A.: Investigation of the optical backscattering to scattering ratio of marine particles in relation to their biogeochemical composition in the east- ern English Channel and southern North Sea, Limnol. Oceanogr., 52(2), 739-752, 2007

Maffione, R. A. and Dana, D. R.: Instruments and methods for measuring the backward-scattering coefficient of ocean waters, Appl. Opt., 36, 6057-6067, 1997.

Malinverno, E., Ziveri, P., and Corselli, C.: Coccolithophorid distribution in the Ionian Sea and its relationship to eastern Mediterranean circulation during late fall to early winter 1997 , J. Geophys. Res., 108(C9), 8115, doi:10.1029/2002JC001346, 2003.

McNeil, G. T.: Metrical fundamentals of underwater lens systems, Opt. Eng., 16, 128-139, 1977.

Molfino, B. and McIntyre, A.: Precessional forcing of nutricline dynamics in the Equatorial Atlantic, Science, 249, 766-768, 1990.

Moore, C., Twardowski, M. S., and Zaneveld, J. R. V.: The ECO VSF - A multi-angle scattering sensor for determination of the volume scattering function in the backward direction, Proc. Ocean Optics XV, 16-20 October, Monaco, Office Naval Research, USA, CD-ROM, 2000.

Morel, A.: Etude expérimentale de la diffusion de la lumie're par 1_eau, le solutions de chlorure de sodium et l'eau de mer optiquement pure, J. Chim. Phys., 10, 1359-1366, 1966.

Morel, A.: Note au sujet des constants de diffusion de la lumiere pour l'eau et l'eau de mer optiquement pures, Cahiers Oceanographique, 20, 157-162, 1968.

Morel, A.: Diffusion de la lumiere par les eaux de mer. Resultats experimentaux et approche theorique, in Optics of the Sea, AGARD Lecture Series No. 61, NATO, 3.1.1-3.1.76, 1973.

Morel, A.: Optical properties of pure water and pure seawater, in: Optical aspects of Oceanography, edited by: Jerlov, N. G. and Steemann Nielson, E., Academic, New York, 1-24, 1974.

Morel, A.: Optical modeling of the upper ocean in relation to its biogenous matter content (Case I waters), J. Geophys. Res., 93, 10 749-10768, 1988.

Morel, A. and Gentili, B.: Diffuse reflectance of oceanic waters: its dependence on sun angle as influenced by the molecular scattering contribution, Appl. Opt., 30, 4427-4438, 1991.

Morel, A. and Gentili, B.: Radiation transport within oceanic (case 1) waters, J. Geophys. Res., 109, C06008, doi:10.1029/2003JC002259, 2004.

Morel, A., Gentili, B., Claustre, H., Babin, M., Bricaud, A., Ras, J., and Tieche, F.: Optical properties of the "clearest" natural waters, Limnol Oceanogr., 52, 217-229, 2007.

O'Conner, C. L. and Schlupf, J. P.: Brillouin scattering in water: the Landau-Paszek ratio, J. Chem. Phys., 47, 31-38, 1967.

Oubelkheir, K., Clementson, L., Webster, I., Ford, P., Dekker, A., Radke, L., and Daniel, P.: Using inherent optical properties to investigate biogeochemical dynamics in a tropical macro-tidal coastal system, J. Geophys. Res., 111, C07021, doi:10.1029/2005JC003113, 2006.

Pegau, W. S., Boss, E., Weidemann, A., Korotaev, G., Lee, M., and Shibanov, E.: Measurements of the backscattering coefficient, Abstract from ASLO meeting, Session CS24 - Optics, Albuquerque, NM, 12-16 February, 2001.

Pope, R. M. and Fry, E. S.: Absorption spectrum (380-700 nm) of pure water. II. Integrating cavity measurements, Appl. Opt., 36, 8710-8723, 1997.

Prentice, J. E., Weidemann, A. D., Pegau, W. S., Voss, K. J., Lee, M. E., Shybanov, E., Martynov, O., Laux, A. E., Briggs, A., and Chang, G.: Laboratory comparisons of optical scattering instru- 
mentation, Ocean Optics XVI, Santa Fe, New Mexico, 2002.

Ras, J., Claustre, H., and Uitz, J.: Spatial variability of phytoplankton pigment distributions in the Subtropical South Pacific Ocean: comparison between in situ and predicted data, Biogeosciences Discuss., 4, 3409-3451, 2007, http://www.biogeosciences-discuss.net/4/3409/2007/.

Siegel, D. A., Dickey, T. D., Washburn, L., Hamilton, M. K., and Mitchell, B. G.: Optical determination of particulate abundance and production variations in the oligotrophic ocean, Deep Sea Res. Part A, 36, 211-222, 1989.

Shifrin, K.: Physical optics of ocean water, American Institute of Physics, New York, 285 pp., 1988.

Slade, W. H. and Boss, E.: Calibrated near-forward volume scattering function obtained from the LISST particle sizer, Opt. Express, 14(8), 3602-3615, 2006.

Smith, R. C. and Baker, K. S.: Optical properties of the clearest natural waters (200-800 nm), Appl. Opt., 20(2), 177-184, 1981.

Stramska, M. and Stramski, D.: Variability of particulate organic carbon concentration in the north polar Atlantic based on ocean color observations with Sea-viewing Wide Fieldof-view Sensor (SeaWiFS), J. Geophys. Res., 110, C10018, doi:10.1029/2004JC002762, 2005.

Stramski, D., Reynolds, R., Babin, M., Kaczmarek, S., Lewis, M. R., Rottgers, R., Sciandra, A., Stramska, M., Twardowski, M. S., and Claustre, H.: Relationship between the surface concentration of particulate organic carbon and optical properties in the eastern South Pacific and eastern Atlantic Oceans, Biogeosciences Discuss., 2007.

Stramski, D. and Kiefer, D. A.: Light scattering by microorganisms in the open ocean, Prog. Oceanogr., 28, 343-383, 1991.

Stramski, D., Reynolds, R. A., Kahru, M., and Mitchell, B. G.: Estimation of particulate organic carbon in the ocean from satellite remote sensing, Science, 285, 239-242, 1999.

Stramski, D., Bricaud, A., and Morel, A.: Modeling the inherent optical properties of the ocean based on the detailed composition of the planktonic community, Appl. Opt., 40, 2929-2945, 2001.

Stramski, D., Boss, E., Bogucki, D., and Voss, K.: The role of seawater constituents in light backscattering in the ocean, Prog. Oceanogr., 61, 27-56, 2004.

Sullivan, J. M., Twardowski, M. S., Donaghay, P. L., and Freeman, S. A.: Using Scattering Characteristics to Discriminate Particle Types in US Coastal Waters, Appl. Opt., 44, 1667-1680, 2005.
Sullivan, J. M., Twardowski, M. S., Zaneveld, J. R. V., Moore, C., Barnard, A., Donaghay, P., and Rhoades, B.: The hyperspectral temperature and salinity dependencies of absorption by water and heavy water in the $400-750 \mathrm{~nm}$ spectral range, Appl. Opt., 45, 5294-5309, 2006.

Twardowski, M. S., Sullivan, J. M., Donaghay, P. L., and Zaneveld, J. R. V.: Microscale quantification of the absorption by dissolved and particulate material in coastal waters with an ac-9, J. Atmos. Ocean. Technol., 16(12), 691-707, 1999.

Twardowski, M. S., Boss, E., Macdonald, J. B., Pegau, W. S., Barnard, A. H., and Zaneveld, J. R. V.: A model for estimating bulk refractive index from the optical backscattering ratio and the implications for understanding particle composition in Case I and Case II waters, J. Geophys. Res., 106(C7), 14 129-14 142, 2001.

Twardowski, M. S., Lewis, M., Barnard, A., and Zaneveld, J. R. V.: In-water instrumentation and platforms for ocean color remote sensing applications, in: Remote Sensing of Coastal Aquatic Waters, edited by: Miller, R., Del Castillo, C., and McKee, B., Springer Publishing, Dordrecht, Netherlands, 69-100, 2005.

Twardowski, M. S., Sullivan, J. S., Dierssen, H., and Zaneveld, J. R. V.: Sources of backscattering in marine waters, Ocean Sciences Meeting, Honolulu, HI, February 20-24, Abstract OS32M-02, 2006.

Ulloa, O., Sathyendranath, S., and Platt, T.: Effect of the particlesize distribution on the backscattering ratio in seawater, Appl. Opt., 33, 7070-7077, 1994.

Volten, H., de Haan, J. F., Hovenier, J. W., Schreurs, R., and Vassen, W.: Laboratory measurements of angular distributions of light scattered by phytoplankton and silt, Limnol. Oceanogr., 43, 1180-1197, 1998.

Walsh, I., Chung, S. P., Richardson, M. J., and Gardner, W. D.: The diel cycle in the integrated particle load in the equatorial Pacific: a comparison with primary production, Deep Sea Res. II, 42, 465-477, 1995.

Zaneveld, J. R. V., Kitchen, J. C., and Moore, C. M.: The scattering error correction of reflecting-tube absorption meters, Ocean Optics XII, Proc. SPIE 2258, 44-55, 1994.

Zaneveld, J. R. V., Twardowski, M. S., Lewis, M., and Barnard, A.: Radiative transfer and remote sensing, in: Remote Sensing of Coastal Aquatic Waters, edited by: Miller, R. and Del-Castillo, C., Springer-Kluwer Publishing, 1-20, 2005. 